\title{
Trans-mutation at Gold(III): A Mechanistic Study of a Catalytic Acetylene Functionalization via a Double Insertion Pathway
}

\author{
Marte Sofie Martinsen Holmsen, ${ }^{\dagger}$ Ainara Nova, ${ }^{\ddagger *}$ David Balcells, ${ }^{\ddagger}$ Eirin Langseth, ${ }^{\dagger}$ Sigurd \\ Øien-Ødegaard, ${ }^{\dagger}$ Richard H. Heyn,${ }^{\S}$ Mats Tilset, ${ }^{\dagger *}$ Gábor Laurenczy ${ }^{\perp}$
}

${ }^{\dagger}$ Department of Chemistry and ${ }^{\ddagger}$ Centre for Theoretical and Computational Chemistry (CTCC), Department of Chemistry, University of Oslo, P.O. Box 1033 Blindern, N-0315 Oslo, Norway ${ }^{\S}$ SINTEF Materials and Chemistry, P.O. Box 124 Blindern, N-0314 Oslo, Norway ${ }^{\perp}$ Institut des Sciences et Ingénierie Chimiques, Ecole Polytechnique Fédérale de Lausanne, CH-1015 Lausanne, Switzerland

${ }^{\#}$ Current address: SINTEF Materials and Chemistry, P.O. Box 124 Blindern, N-0314 Oslo, Norway

Corresponding authors: mats.tilset@kjemi.uio.no, ainara.nova@kjemi.uio.no

\begin{abstract}
The $\mathrm{Au}(\mathrm{III})$ complex $\mathrm{Au}\left(\mathrm{OAc}^{\mathrm{F}}\right)_{2}(\mathrm{tpy})\left(\mathrm{OAc}^{\mathrm{F}}=\mathrm{OCOCF}_{3}\right.$; tpy = 2-(p-tolyl $)$ pyridine $)$ catalyzes the anti addition of trifluoroacetic acid $\left(\mathrm{HOAc}^{\mathrm{F}}\right)$ to acetylene to furnish vinyl trifluoroacetate. The $\mathrm{Au}(\mathrm{III})$ vinyl complex $\mathrm{Au}(\mathrm{tpy})\left(\mathrm{OAc}^{\mathrm{F}}\right)\left(\mathrm{CH}=\mathrm{CHOAc}^{\mathrm{F}}\right)$ (vinyl group bonded trans to tpy- $N$ ) is formed during the early stage of the reaction. The vinyl complex, which has been isolated and structurally characterized, resists protolytic cleavage of the vinyl group and therefore catalysis does not proceed by a simple formal insertion (i.e. coordinationnucleophilic attack-protolysis at the site trans to tpy- $N$ ) mechanism. Experimental evidence, including isotopic labeling, rather suggests that a double-insertion process is operative. The unobserved $\mathrm{Au}$ (III) divinyl complex $\mathrm{Au}$ (tpy) $\left(\mathrm{CH}=\mathrm{CHOAc}^{\mathrm{F}}\right)_{2}$ is a crucial intermediate for which the true catalytic activity, comprising a coordination-nucleophilic attack-protolysis sequence, occurs at the site trans to tpy- $C$. The overall mechanism is in full agreement with DFT calculations and is a result of the considerable differences in the kinetic and thermodynamic trans effects of tpy- $N$ vs. tpy- $C$ on each reaction step. The computational data provide a rationale for the catalytic functionalization of acetylene trans to tpy- $C$, whereas
\end{abstract}


ethylene (previously reported) only undergoes a stoichiometric insertion, and then comes to a full stop, trans to tpy- $N$.

Keywords:

Acetylene functionalization

Cyclometalated complexes

$\mathrm{Au}(\mathrm{III})$ catalysis

$\mathrm{Au}(\mathrm{III})$ vinyl complexes

DFT calculations

Reaction mechanisms

Trans effects 


\section{INTRODUCTION}

The functionalization of alkenes and alkynes under mild conditions is of great practical and economic interest because readily available hydrocarbons may be converted to value-added products. Such processes may be catalyzed by a plethora of metals and metal complexes, and gold is especially recognized and attractive due to its ability to $\pi$-coordinate alkenes and alkynes, causing them to be activated towards nucleophilic attack. ${ }^{1-17}$ This has given rise to a virtual explosion in the use of gold complexes to catalyze the chemical transformation of alkenes, alkynes, and other unsaturated compounds during the last decade. The use of gold complexes quickly matured to find applications in the catalytic transformations of multiply functionalized precursors to complex organic structures. Less attention has been paid to elucidate the details of the reactivities of the smallest alkenes and alkynes, i.e. ethylene and acetylene, at gold complexes.

Acetylene has become less utilized as a potential $\mathrm{C}_{2}$ building block for production of commodity chemicals due to the availability of less expensive hydrocarbons from petrochemical feedstocks. However, vinyl chloride is produced in China on a large scale by acetylene hydrochlorination, with the use of mercury catalysts. ${ }^{18,19}$ The use of mercury raises obvious environmental concerns, and alternatives are thus considered. This has led to attempts at developing analogous chemistry using supported gold catalysts. The acetylene hydrochlorination process, described by Hutchings and coworkers and others, is a classic case in this regard. ${ }^{18-23}$ Mechanistically, Hutchings and coworkers have proposed on the basis of experiments and computations, that a coordination-nucleophilic attack mechanism, analogous to that in Scheme 1, path A is operative. For the hydrotrifluoroacetylation of acetylene, mercury based processes have been described in the patent literature, ${ }^{24,25}$ but to our knowledge, no Au catalyzed process has been reported. 


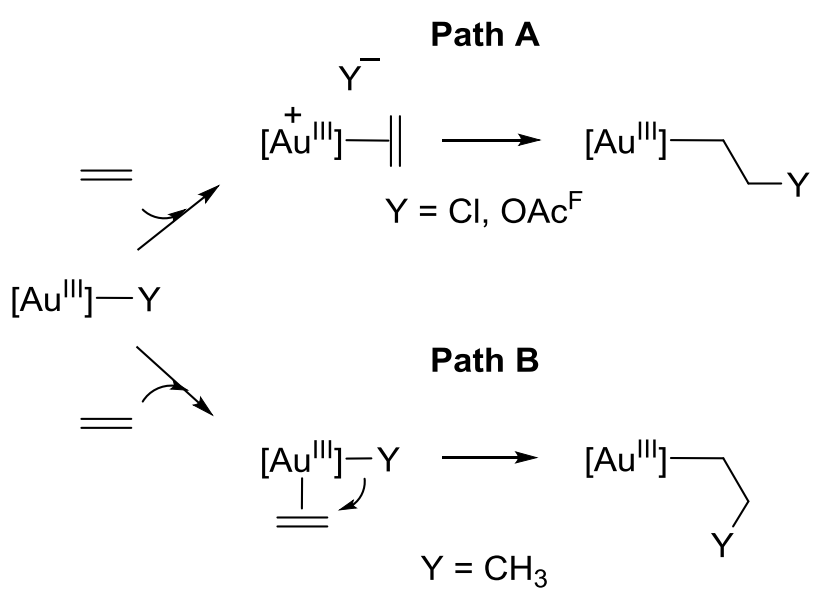

Scheme 1. Possible pathways for the insertion of an olefin into a $\left[\mathrm{Au}^{\mathrm{III}}\right]-\mathrm{Y}$ bond $\left(\mathrm{Y}=\mathrm{Cl}, \mathrm{OAc}^{\mathrm{F}}, \mathrm{CH}_{3} ; \mathrm{OAc}^{\mathrm{F}}=\mathrm{OCOCF}_{3}\right)$.

Although the differences between $\mathrm{Au}(\mathrm{I})$ and $\mathrm{Au}(\mathrm{III})$ catalysis can be profound, ${ }^{26}$ studies on $\mathrm{Au}(\mathrm{I})$ continue to strongly dominate the field, in part due to the relative paucity of efficient and robust protocols for preparation of $\mathrm{Au}(\mathrm{III})$ complexes. $\mathrm{Bi}$ - and tridentate ligands, including cyclometalated ones, have proven particularly useful to support $\mathrm{Au}(\mathrm{III})$ species. ${ }^{27-30}$ Catalytic transformations involving $\mathrm{Au}(\mathrm{I}) / \mathrm{Au}(\mathrm{III})$ redox cycles for effecting $\mathrm{C}-\mathrm{C}$ and $\mathrm{C}$ heteroatom bond forming reactions at alkenes and alkynes have attracted considerable recent attention, ${ }^{31-36}$ including alkyne functionalization with Selectfluor. ${ }^{31,37-42}$

The intermediacy of $\mathrm{Au}(\mathrm{III})$ alkene and alkyne complexes in these catalytic transformations is evident. Nevertheless, there has to date appeared only one report ${ }^{43}$ of a structurally characterized $\mathrm{Au}(\mathrm{III})$ alkene complex, $\mathrm{AuMe}_{2}(\mathrm{cod})^{+}$, and two additional reports on the isolation and/or NMR observation of $\mathrm{Au}(\mathrm{III})$ alkene complexes that are supported by formally dianionic, $\mathrm{C}^{\wedge} \mathrm{N}^{\wedge} \mathrm{C}$ pincer-type ligands. ${ }^{44,45} \mathrm{Au}(\mathrm{III})$ alkyne complexes remain elusive, although such species are frequently invoked in catalytic and stoichiometric transformations and have been explored by computational means. ${ }^{46,47}$ We recently reported a theoretical study of the detailed bonding, electronic structures, and reactivity patterns of simple $\mathrm{Au}(\mathrm{III})$ model compounds of the type $\mathrm{AuX}_{3}(\mathrm{~L})$ and $\mathrm{AuX}_{2}(\mathrm{~L})_{2}{ }^{+}$, where $\mathrm{L}=\mathrm{C}_{2} \mathrm{H}_{4}$ or $\mathrm{C}_{2} \mathrm{H}_{2}$, and $\mathrm{X}=\mathrm{H}, \mathrm{Me}$, or $\mathrm{Cl}^{15}$

The mechanism for the insertion of ethylene into an $\mathrm{Au}-\mathrm{O}$ bond of $\mathrm{Au}(\mathrm{tpy})\left(\mathrm{OAc}^{\mathrm{F}}\right)_{2}(\mathbf{1}$; tpy $=2$-( $p$-tolyl $)$ pyridine, Scheme 2$)$ was explored by our group by combining experiments and DFT calculations. ${ }^{48}$ This non-oxidative functionalization of ethylene which leads to Cheteroatom bond formation proceeds mechanistically as a formal insertion via ethylene coordination followed by attack by external nucleophile (Scheme 1, path A), as opposed to 
the $\mathrm{C}-\mathrm{C}$ bond forming coordination-insertion reactions recently investigated, experimentally and computationally, by Bourissou and coworkers ${ }^{45,49-51}$ (Scheme 1, path B). Similar formal insertions have been reported by the groups of Atwood ${ }^{52}$ and Bochmann. ${ }^{44}$ Selective insertion of ethylene into the Au-O bond trans to $\mathrm{N}$ of the chelating tpy ligand furnished $\mathrm{Au}$ (tpy) $\left(\mathrm{CH}_{2} \mathrm{CH}_{2} \mathrm{OAc}^{\mathrm{F}}\right)\left(\mathrm{OAc}^{\mathrm{F}}\right)(2$, Scheme 2$)$. Although the trans to tpy- $C$ coordination site is kinetically more accessible, the trans to tpy- $N$ insertion product is thermodynamically favored. Unfortunately, a catalytic process could not be achieved with this system, because protolytic cleavage of the $\mathrm{Au}-\mathrm{C}\left(\mathrm{sp}^{3}\right)$ bond in $\mathbf{2}$ does not occur.

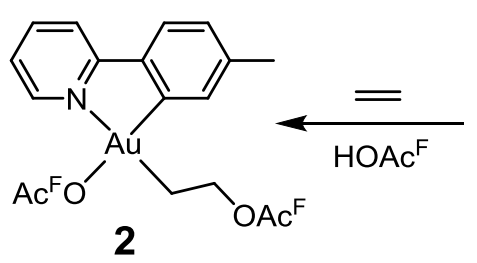

2

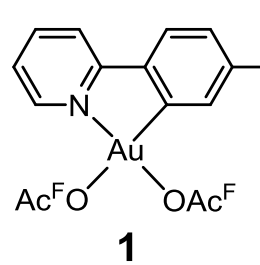

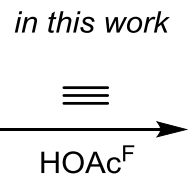

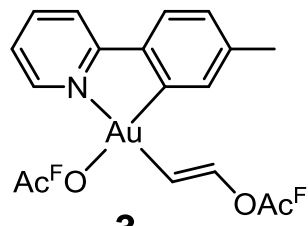

3

active catalyst for acetylene trifluoroacetoxylation

Scheme 2. Formal insertion of ethylene and acetylene at $\mathrm{Au}\left(\mathrm{OAc}^{\mathrm{F}}\right)_{2}(\mathrm{tpy})$.

In this paper, we report that $\mathrm{Au}(\operatorname{tpy})\left(\mathrm{OAc}^{\mathrm{F}}\right)_{2}(\mathbf{1})$, in contrast to its stoichiometric reactivity towards ethylene, causes the catalytic formation of vinyl trifluoroacetate by the anti addition of trifluoroacetic acid, $\mathrm{HOAc}^{\mathrm{F}}$, to acetylene. A detailed, combined experimental and computational study unravels an unexpected complexity in this catalytic transformation. The combined evidence suggests that this reaction proceeds via a double insertion pathway, in which the first acetylene inserted product (3; Scheme 2) is the active catalyst involving an unobserved $\mathrm{Au}(\mathrm{III})$ divinyl species as a crucial intermediate. The potential feasibility of an analogous reaction pathway with ethylene as the substrate has also been analyzed. 


\section{RESULTS AND DISCUSSION}

Reactions of $\mathrm{Au}(\mathbf{t p y})\left(\mathrm{OAc}^{\mathrm{F}}\right)_{2}$ with Acetylene. When acetylene was bubbled through a solution of $\mathbf{1}$ in trifluoroacetic acid- $d\left(\mathrm{DOAc}^{\mathrm{F}}\right)$ at ambient temperature and pressure, an immediate reaction occurred. A ${ }^{1} \mathrm{H}$ NMR spectrum (Figure S21, ESI) acquired less than 5 min after mixing revealed that ca. $50 \%$ of 1 had reacted to furnish the vinyl complex $\mathrm{Au}(\mathrm{tpy})\left(\mathrm{OAc}^{\mathrm{F}}\right)\left(\mathrm{CH}=\mathrm{CHOAc}^{\mathrm{F}}\right)(3)$ (Scheme 3). The complete ${ }^{1} \mathrm{H}$ NMR spectra (vide infra) of 3 established that the formal insertion of acetylene into one of the $\mathrm{Au}-\mathrm{O}$ bonds has taken place selectively trans to tpy- $N$ and in an anti fashion. This parallels the selectivity features of the ethylene insertion at $\mathbf{1}$ previously described. ${ }^{48}$ In addition, signals due to the vinyl protons in $(E)$-vinyl trifluoroacetate- $d(4-d)\left(\delta 5.19\right.$ and 7.18, mutually coupled with trans $^{3} J_{\mathrm{HH}}=13.6$ $\mathrm{Hz}$ ) were seen. The yield of $4-\boldsymbol{d}$, determined from NMR integration against an internal standard, was ca. $20 \%$ based on the initial amount of $\mathbf{1}$. Finally, traces of $(1 E, 3 E)-1,4-$ bis(trifluoroacetoxy)-1,3-butadiene (5) and $\mathrm{D}_{2} \mathrm{tpy}^{+}$were detected. It will be seen that 4- $\boldsymbol{d}$ production is catalyzed by $\mathrm{Au}(\mathrm{III})$ and that $\mathbf{5}$ and $\mathrm{D}_{2}$ tpy ${ }^{+}$results from catalyst deactivation, initiated by protolytic cleavage of the Au-C and $\mathrm{Au}-\mathrm{N}$ bonds of the Au(tpy) moiety. ${ }^{43}$ After $30 \mathrm{~min}$, all of $\mathbf{1}$ had reacted and $\mathbf{3}$ was the only $\mathrm{Au}(\mathrm{tpy})$-containing species seen in solution. The yield of 4- $\boldsymbol{d}$ (NMR integration) now corresponded to ca. $200 \%$, based on the initial amount of $\mathbf{1}$. NMR signals due to $\mathbf{5}$ had grown in prominence (ca. $40 \%$ of the quantity of $\mathbf{3}$ ). The amount of $\mathrm{D}_{2}$ tpy ${ }^{+}$had increased to ca. $50 \%$ of the quantity of $\mathbf{3}$. The reaction was monitored by ${ }^{1} \mathrm{H}$ NMR for $24 \mathrm{~h}$, at which time 4-d (along with traces of $\mathbf{4}$ ), $\mathbf{5}$, and $\mathrm{D}_{2} \mathrm{tpy}^{+}$ were the only species that could be detected and all $\mathbf{3}$ had decomposed. At this point, $\mathrm{D}_{2} \mathrm{tpy}^{+}$ and 5 had formed in essentially quantitative yields. No other significant changes occurred after extended reaction times. The estimated turnover numbers for production of $\mathbf{4}-\boldsymbol{d}$, based on integration of the NMR signals of $4-\boldsymbol{d}$ against the signal of an internal standard in multiple experiments, were 13-15 per Au (see Table S1, ESI). A control experiment established that no reaction occurred between acetylene and $\mathrm{DOAc}^{\mathrm{F}}$ in the absence of $\mathbf{1}$ or other sources of $\mathrm{Au}$ on the time scale of these reactions. Clearly, Au species must be involved in what amounts to a catalytic transformation of acetylene into vinyl trifluoroacetate.

In a complementary experiment, 1 was treated with acetylene and non-deuterated trifluoroacetic acid, $\mathrm{HOAc}^{\mathrm{F}}$, in $\mathrm{CD}_{2} \mathrm{Cl}_{2}\left(\mathrm{CD}_{2} \mathrm{Cl}_{2}: \mathrm{HOAc}^{\mathrm{F}}, 6: 1(\mathrm{v}: \mathrm{v})\right)$, and the same products were qualitatively formed; as expected, 4 and $\mathrm{H}_{2} \mathrm{tpy}^{+}$were now formed with no D incorporation. The highest turnover numbers (21-24; see Table S1, ESI) were obtained in this solvent mixture when acetylene was added at $0{ }^{\circ} \mathrm{C}$ before the reaction was monitored at 
ambient temperature. This may be a result of combined effects of increased acetylene solubility, larger production of $\mathbf{3}$, and possibly slower rates of catalyst deactivation at the lower temperature.

The identity of $\mathbf{4}$ was confirmed by ${ }^{1} \mathrm{H}$ NMR analysis of a product mixture that was spiked with a commercial sample. The disubstituted butadiene 5 has neither been isolated nor been previously described, but its identity was inferred from the ${ }^{1} \mathrm{H}$ NMR spectrum as well as COSY spectra. The ${ }^{1} \mathrm{H}$ NMR spectrum of $\mathbf{5}$ exhibited a well-defined signal, attributed to the

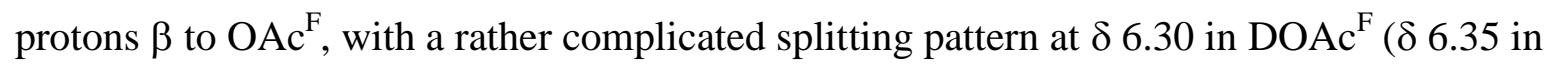
$\mathrm{CD}_{2} \mathrm{Cl}_{2}$, see Figures S22 and S25, ESI). A ${ }^{1} \mathrm{H}^{-}{ }^{1} \mathrm{H}$ COSY experiment (Figure S24, ESI) demonstrated that this signal couples with another signal, attributed to the protons $\alpha$ to $\mathrm{OAc}^{\mathrm{F}}$, further downfield at ca. $\delta 7.4$ in $\operatorname{DOAc}^{\mathrm{F}}$ ( $\delta$ ca. 7.5 in $\mathrm{CD}_{2} \mathrm{Cl}_{2}$ ). Although the latter in part overlaps with signals from the tpy ligand, the signal appears to have the same intensity and symmetrical appearance as the one at $\delta 6.30$. The observed spectrum, in particular the splitting pattern, strongly resembles that of the non-fluorinated analogue of $\mathbf{5},(1 E, 3 E)-1,4-$ diacetoxy-1,3-butadiene (see Figure S27, ESI).
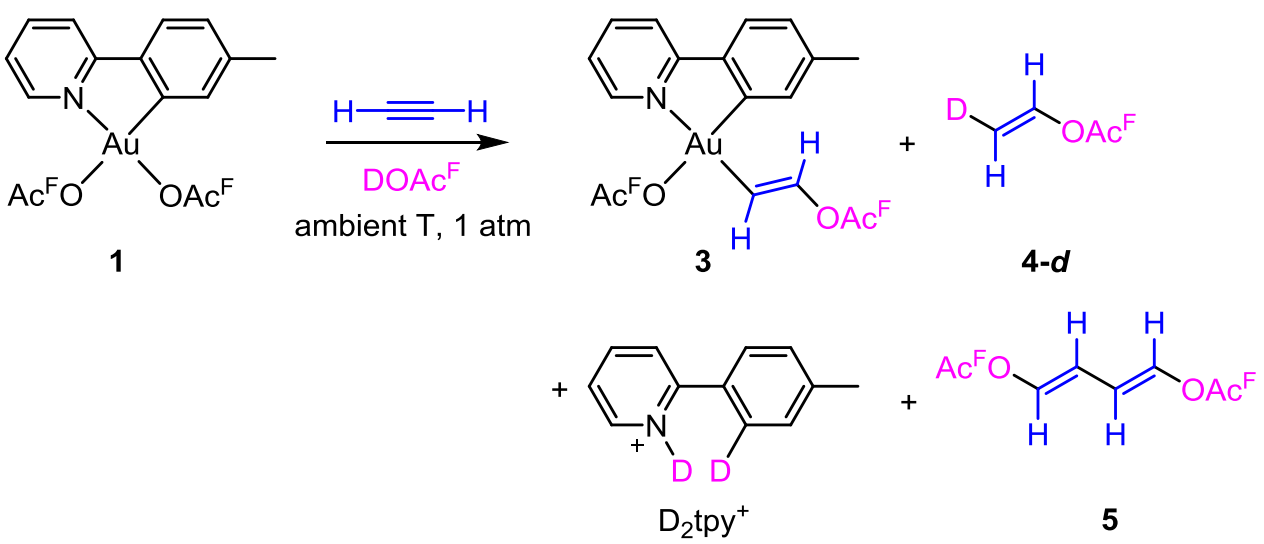

Scheme 3. Reaction between 1 and acetylene in $\mathrm{DOAc}^{\mathrm{F}}\left(\mathrm{OAc}^{\mathrm{F}}=\mathrm{OCOCF}_{3}\right)$. See text for details.

\section{Preparation and Spectroscopic and Structural Characterization of the Acetylene} Insertion Product 3. No $\mathrm{Au}(\mathrm{III}) \pi$-coordinated acetylene complex could be observed by ${ }^{1} \mathrm{H}$ NMR during these reactions, neither at room temperature nor upon lowering the temperature to $-60{ }^{\circ} \mathrm{C}$ in $\mathrm{CD}_{2} \mathrm{Cl}_{2}$. A hypothetic acetylene $\pi$-complex must therefore be promptly captured by $\mathrm{HOAc}^{\mathrm{F}}$ or ${ }^{-} \mathrm{OAc}^{\mathrm{F}}$ to furnish 3. This vinyl complex appears to be a plausible intermediate in the catalytic cycle, as a protolytic cleavage of its vinyl group with $\mathrm{HOAc}^{\mathrm{F}}$ would produce vinyl trifluoroacetate. This would regenerate $\mathbf{1}$ and close the rather simple, putative catalytic cycle depicted in Scheme 4. The diene $\mathbf{5}$ as well as $\mathrm{H}_{2} \mathrm{tpy}^{+}$would result from catalyst 
decomposition under the acidic conditions. In order to investigate the possibility of this mechanism, we sought to isolate and further investigate the observed insertion product 3 .

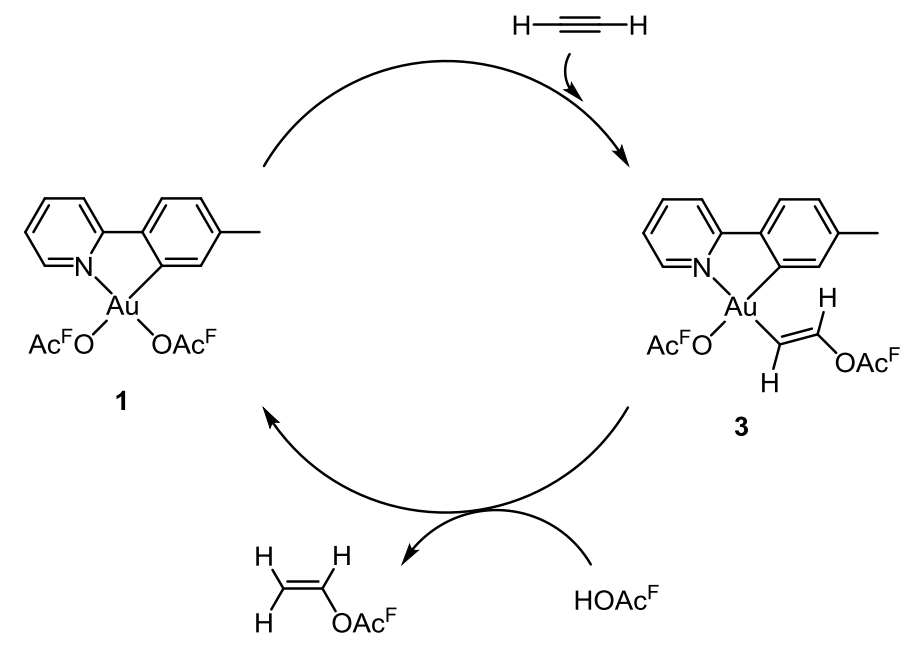

Scheme 4. Simplified, putative catalytic cycle for the trifluoroacetylation of acetylene.

When acetylene was bubbled through a solution of $\mathbf{1}$ in $\operatorname{HOAc}^{\mathrm{F}}$ at $0{ }^{\circ} \mathrm{C}$, the insertion reaction still proceeded smoothly, whereas the catalytic production of vinyl trifluoroacetate proceeded at a considerably slower rate. From the resulting solution, the insertion product 3 was isolated in moderate (40-42\%) yields (Scheme 5).

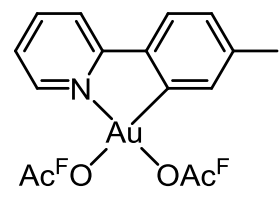

1

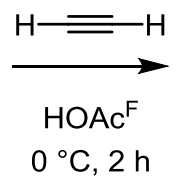

$0{ }^{\circ} \mathrm{C}, 2 \mathrm{~h}$

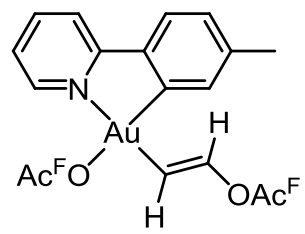

$3(40-42 \%)$

Scheme 5. Synthesis of Au(III) vinyl complex 3.

The ${ }^{1} \mathrm{H}$ NMR spectrum of isolated $\mathbf{3}$ was in perfect agreement with that observed in the NMR-scale experiments. The formal insertion of acetylene trans to tpy- $N$ was supported by a ${ }^{1} \mathrm{H}-{ }^{1} \mathrm{H}$ NOESY experiment which revealed a clear NOE correlation between the vinylic proton $\alpha$ to $\mathrm{Au}(\delta 6.43)$ and the proton $\beta$ to $\mathrm{Au}(\delta 7.31)$ in the tolyl part of the tpy ligand (proton $\mathrm{H}^{6}$ ' in ESI, Figure S8). The ${ }^{19} \mathrm{~F}$ NMR spectrum of $\mathbf{3}$ in dichloromethane- $d_{2}$ showed two well-defined, sharp peaks at $\delta\left({ }^{19} \mathrm{~F}\right)=-77.1$ and -77.5 (Figure 1, top). A ${ }^{19} \mathrm{~F}-{ }^{1} \mathrm{H}$ HOESY experiment showed that the $\delta-77.1$ signal arises from the $\mathrm{OAc}{ }^{\mathrm{F}}$ ligand trans to tpy- $C$ (See ESI, Figure S10). Addition of ca. 1 equiv of $\mathrm{HOAc}^{\mathrm{F}}$ to the solution caused the signal at $\delta-$ 77.1 to undergo significant broadening, whereas free $\mathrm{HOAc}^{\mathrm{F}}$ gave rise to a broadened signal at $\delta-78.2$ (Figure 1, bottom). This broadening suggests the kinetic availability of the coordination site trans to tpy- $C$ and exchange of this $\mathrm{OAc}^{\mathrm{F}}$ ligand with free trifluoroacetic 
acid. These spectroscopic features are in close agreement with those of the ethylene insertion product, $2 .{ }^{48}$ Furthermore, our previous investigation of $\mathbf{1}$ by ${ }^{19} \mathrm{~F}$ NMR demonstrated that the $\mathrm{OAc}^{\mathrm{F}}$ ligand trans to tpy- $C$ exclusively undergoes fast and reversible dissociation in polar media on the NMR time scale. ${ }^{48}$ Thus, a kinetic labilization of the $\mathrm{OAc}^{\mathrm{F}}$ ligands trans to tpy-C are consistently seen in $\mathbf{1}, \mathbf{2}$, and $\mathbf{3}$, in accord with a greater kinetic trans effect of tpy- $C$ than tpy- $N$. Importantly, this provides an additional coordination site for incoming substrates. Our recent report on a metallacycle formation from $\mathbf{1}$, where both the trans to tpy- $C$ and the trans to tpy- $N$ coordination sites are utilized to incorporate ethylene, acetonitrile, and water, corroborates the availability of this site. ${ }^{53}$
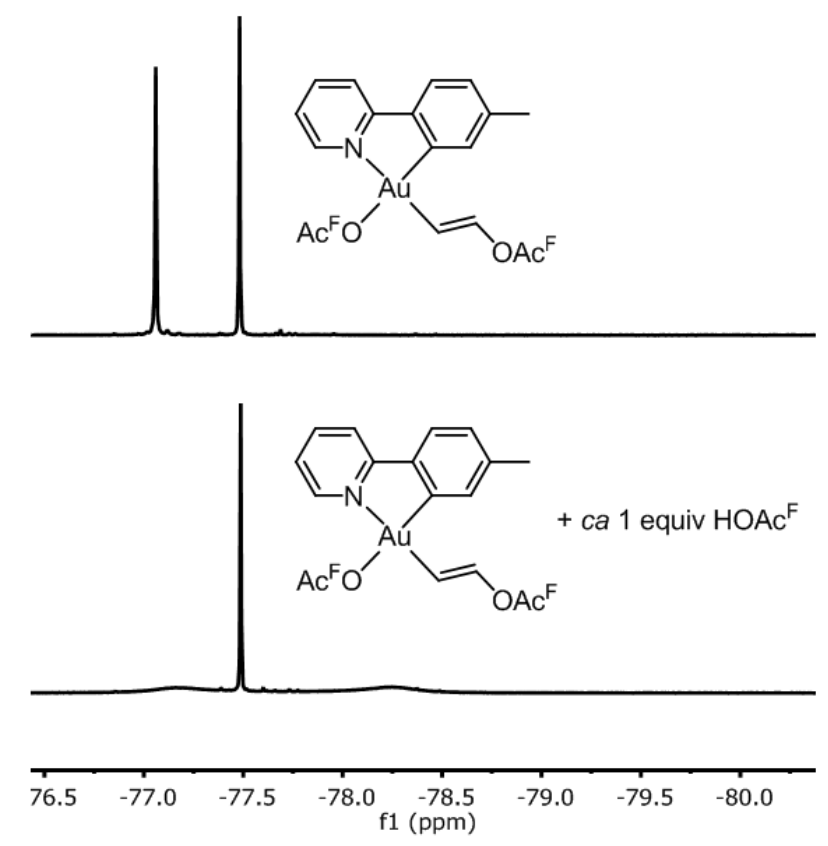

Figure 1. ${ }^{19} \mathrm{~F}$ NMR $\left(188 \mathrm{MHz}, \mathrm{CD}_{2} \mathrm{Cl}_{2}\right.$ ) spectra of $\mathrm{Au}(\mathrm{III})$ vinyl complex 3: (Top) Spectrum of solution of 3 alone. (Bottom) Spectrum of solution of $\mathbf{3}$, after addition of ca. 1 equiv of $\mathrm{HOAc}^{\mathrm{F}}$.

Although $\mathrm{Au}(\mathrm{III})$ vinyl species are invoked as plausible intermediates in $\mathrm{Au}(\mathrm{III})$ mediated reactions,${ }^{54}$ there is still a paucity of well-characterized Au(III) vinyl complexes, ${ }^{55-59}$ only three of which have been structurally characterized. ${ }^{55,57}$ Therefore, the molecular structure of $\mathbf{3}$ was determined by a single-crystal X-ray diffraction analysis. An ellipsoid plot of the structure is shown in Figure 2, along with selected metrical parameters. Detailed crystallographic data and metrical parameters are given in the ESI. ${ }^{60}$ The crystal structure contains two molecules (of which only one is shown in Figure 1) in the asymmetric unit, and also exhibits open channels which contain disordered solvent molecules. The two molecules in the asymmetric unit are almost identical and related by pseudosymmetry (see below and ESI). The complex exhibits the slightly distorted square planar coordination geometry that is 
anticipated for a $d^{8} \mathrm{Au}(\mathrm{III})$ complex, with angular distortions in the square plane as expected for the 5-membered ring chelate structure. Importantly, the molecular structure shows that the formal insertion has occurred trans to tpy- $N$ and with a trans $(E)$ geometry of the resulting vinyl group, in full agreement with the conclusions based on the NMR analysis. The $7.3^{\circ}$ deviation of the C101-Au10-N101 bond angle in the tpy chelate from the idealized 90 to 82.7(5) ${ }^{\circ}$ and the Au-ligand distances Au10-N101, Au10-C101, and Au10-O101 are within the ranges that have previously been reported by us for the related complexes $\mathrm{Au}(\mathrm{tpy})\left(\mathrm{OAc}{ }^{\mathrm{F}}\right)_{2}{ }^{61} \mathrm{Au}(\mathrm{tpy}) \mathrm{Me}_{2},{ }^{61} \mathrm{Au}(\mathrm{tpy})\left(\mathrm{CH}_{2} \mathrm{CH}_{2} \mathrm{OAc}^{\mathrm{F}}\right)\left(\mathrm{OAc}^{\mathrm{F}}\right),{ }^{48} \mathrm{Au}(\mathrm{tpy})-$ $\left(\mathrm{CH}_{2} \mathrm{CH}_{2} \mathrm{OCH}_{2} \mathrm{CF}_{3}\right)\left(\mathrm{OAc}^{\mathrm{F}}\right),{ }^{48}$ and the recently reported metallacycle. ${ }^{53}$ The $\mathrm{Au}-\mathrm{C}\left(\mathrm{sp}^{2}\right)$ bond distance to the vinyl group, Au10-C113, is 2.027(13) $\AA$ which is slightly shorter than the Au$\mathrm{C}\left(\mathrm{sp}^{3}\right)$ bond distances trans to tpy- $N$ in the related complexes, but in the range (2.004(19)2.043(4) $\AA$ ) for $\mathrm{Au}-\mathrm{C}\left(\mathrm{sp}^{2}\right)$ bonds in structurally characterized $\mathrm{Au}(\mathrm{III})$ vinyl species. ${ }^{55,57}$ The C113-C114 bond distance of 1.293(19) $\AA$ is rather close to typical distances in disubstituted $\mathrm{C}=\mathrm{C}$ double bonds (trans 1,2-disubstituted alkenes, averaging 1.312(11) $\AA^{62}$ ), and is the shortest $\mathrm{C}=\mathrm{C}$ bond distance in structurally characterized $\mathrm{Au}(\mathrm{III})$ vinyl complexes (range 1.311(3)-1.344(6) $\AA$ ).$^{55,57}$ The structure of $\mathbf{3}$ displays parallel, displaced $\pi-\pi$ stacking along the $b$ direction, and the relatively short distance between the parallel planes of the tpy ligands alternates between 3.41 and $3.43 \AA$ for the two asymmetric units. 


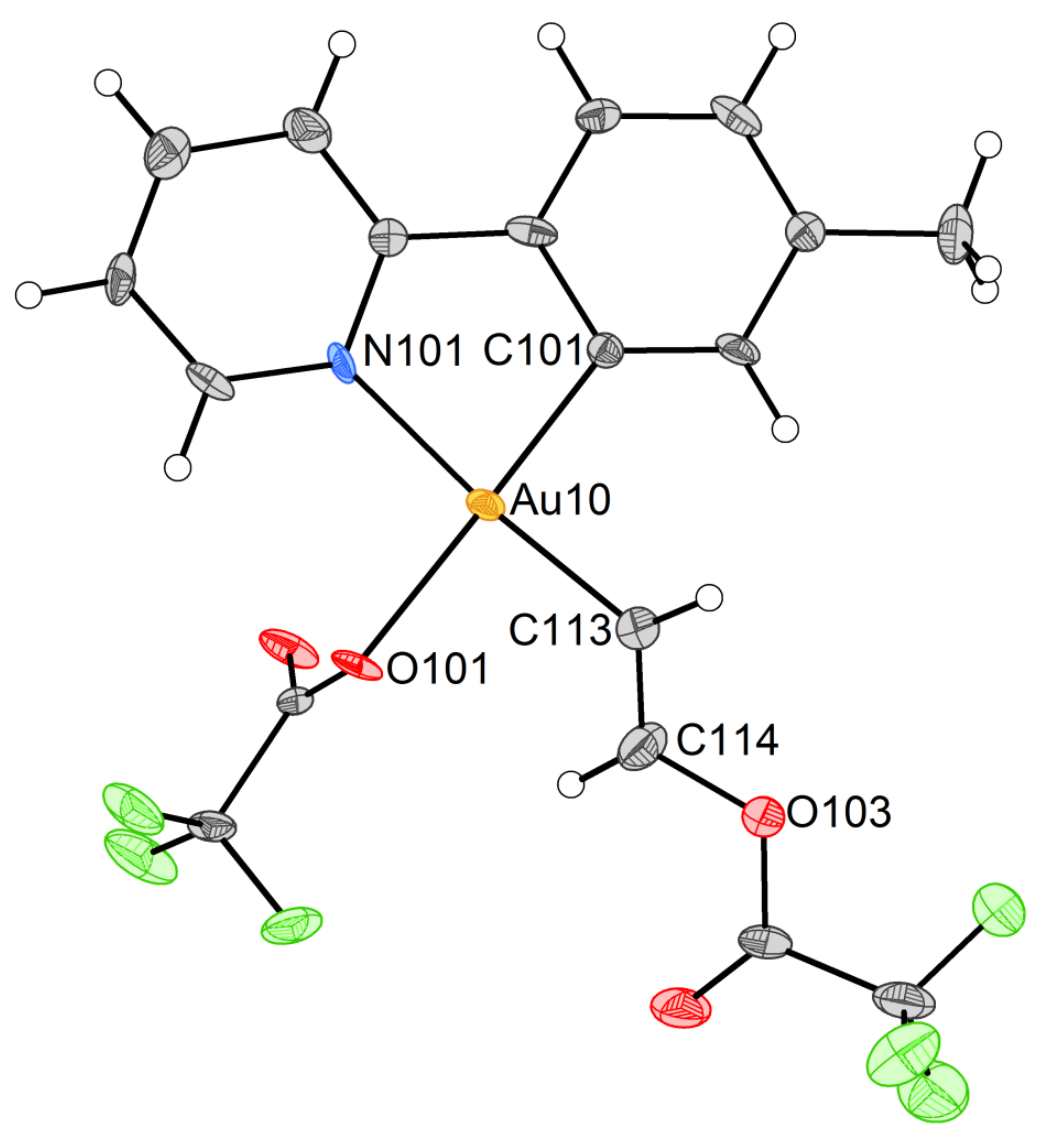

Figure 2. ORTEP drawing of $\mathrm{Au}(\mathrm{III})$ vinyl complex 3, with $50 \%$ probability ellipsoids. Selected bond distances $[\AA]$ and angles [ ${ }^{\circ}$ : Au10-N101, 2.070(11); Au10-C101, 2.007(11); Au10-O101, 2.110(8); Au10-C113, 2.027(13); C113-C114, 1.293(19); C114-O103, 1.450(18); N101-Au10-O101, 96.5(4); C101-Au10-N101, 82.7(5); C101-Au10-C113, 92.2(5); C113Au10-O101, 88.6(5); C101-Au10-O101, 179.0(4); C113-Au10-N101, 173.2(5); Au10-C113-C114, 123.2(11); C113-C114O103, 115.3(14); Au10-C113-C114-O103, 175.7(9). Disordered solvent molecules are omitted for clarity. The asymmetric unit consists of two complexes, and the metrical parameters are given for the complex with the lower uncertainties in the bond distances and bond angles.

\section{On the Involvement of the Acetylene Insertion Product 3 in the Catalytic}

Reaction. The successful isolation of the vinyl complex $\mathbf{3}$ offered unique possibilities to check whether it is indeed an intermediate in the proposed catalytic cycle (Scheme 4). If this were the case, each of the reaction steps - insertion and protolytic cleavage - should proceed at rates that are in accord with the turnover rates of the catalysis. Furthermore, it should be possible to access the same catalytic cycle starting with either $\mathbf{1}$ or $\mathbf{3}$. Since $\mathbf{1}$ and $\mathbf{3}$ coexisted in solution during catalysis starting with $\mathbf{1}$, both species ought to coexist under approximate steady-state conditions after a few turnovers if catalysis according to Scheme 4 is also initiated with 3.

We were therefore surprised when it was found that a solution of the isolated vinyl complex $\mathbf{3}$ in DOAc ${ }^{\mathrm{F}}$ in the absence of acetylene was remarkably stable. Even after days at ambient temperature, there was no hint of conversion of $\mathbf{3}$ into the expected product of 
protolytic cleavage, $1 ; \mathbf{4}-\boldsymbol{d}$ could also not be detected. This observation appears to rule out the simple catalytic mechanism in Scheme 4.

Interestingly, when the solution of 3 in neat $\operatorname{DOAc}^{\mathrm{F}}$ (or in $\mathrm{CD}_{2} \mathrm{Cl}_{2}: \mathrm{HOAc}^{\mathrm{F}}, 6: 1$ (v:v)) was again exposed to acetylene by bubbling through the solution, catalysis ensued; vinyl trifluoroacetate now formed catalytically (estimated turnover numbers after $24 \mathrm{~h}$, ca. 11-12 (12-15 in $\mathrm{CD}_{2} \mathrm{Cl}_{2} / \mathrm{HOAc}^{\mathrm{F}}$ ). Importantly, under these catalytic reaction conditions there was no hint by ${ }^{1} \mathrm{H}$ NMR of 1 or other intermediates - again, seemingly ruling out the mechanism in Scheme 4 . The reaction was monitored by ${ }^{1} \mathrm{H}$ NMR until the catalytic activity ceased. At this point, in addition to NMR signals arising from the $\mathrm{D}_{2} \mathrm{tpy}^{+}$, the tell-tale spectroscopic signatures of the decomposition product 5 were seen (see Figures S22 and S25).

Formation and Characterization of an Au(III) C-bonded Enolate and its Involvement in the Catalytic Reaction. We were intrigued by the observation of the disubstituted butadiene $\mathbf{5}$ after extended reaction times in the catalytic reaction of $\mathbf{1}$ with acetylene. The four-carbon chain of $\mathbf{5}$ must arise from coupling of two acetylenic $\mathrm{C}_{2}$ units. The possible involvement of $\mathbf{1 , 3}, \mathbf{4}$, and acetylene all appeared possible. In order to probe for the involvement of $\mathbf{4}$, a solution of $\mathbf{1}$ in $\mathrm{HOAc}^{\mathrm{F}}$ was treated with 10 equiv of $\mathbf{4}$. A slow reaction ensued which, however, gave no detectable quantities of $\mathbf{5}$ or any other four-carbon coupling products. Instead, during the course of six days a clean transformation of $\mathbf{1}$ to the Cbonded $\mathrm{Au}(\mathrm{III})$ enolate complex 6 (Scheme 6) occurred, without observable intermediates. This new complex, isolated in 51-60\% yield, exhibited a clear NMR fingerprint, with one signal at $\delta 9.92(\mathrm{t}, J=4.6 \mathrm{~Hz})$ for the formyl proton, and the other at $\delta 3.14(\mathrm{~d}, J=4.6 \mathrm{~Hz})$ for the methylene group. When 6 was dissolved in DOAc ${ }^{\mathrm{F}},{ }^{1} \mathrm{H}$ NMR analysis revealed that H/D exchange between the deuterated solvent and the methylene group occurred, presumably via keto/enol tautomerization, evidenced by a decrease of the signal intensity for the methylene group with an approximate half-life of 25 min under these conditions. This was accompanied by apparent loss of coupling and the conversion of the formyl triplet signal into a singlet (see ESI, Figure S20). The mechanism of formation of 6 remains uncertain and has not been further investigated, but may involve the formal insertion of vinyl trifluoroacetate at $\mathbf{1}$ followed by elimination of trifluoroacetic anhydride. Subsequently, it was found that $\mathbf{6}$ also can be obtained from vinyl complex $\mathbf{3}$, simply by a hydrolysis reaction in the presence of $\mathrm{HOAc}^{\mathrm{F}}$. 


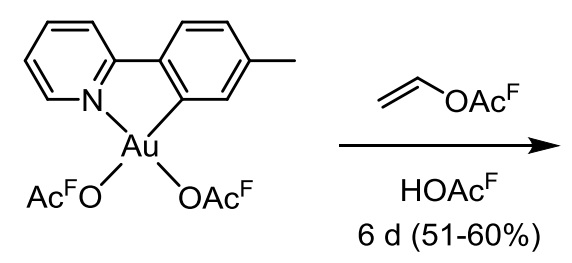

1

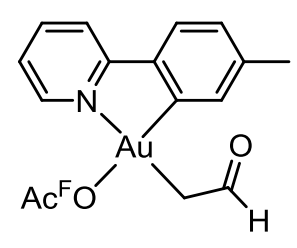

6
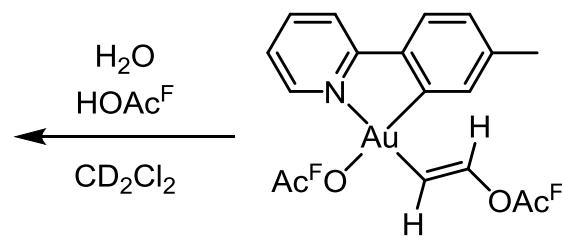

3

Scheme 6. The two routes for generating $\mathrm{Au}(\mathrm{III})$ enolate complex 6.

The rather unexpected enolate complex 6 was subjected to a single-crystal X-ray diffraction analysis. An ellipsoid plot of the molecular structure of $\mathbf{6}$ is shown in Figure 3, along with selected metrical data. Detailed crystallographic data and metrical parameters are given in the ESI. The molecular structure verifies the presence of the enolate ligand trans to tpy- $N$, in agreement with the NMR data. The $\mathrm{OAc} c^{\mathrm{F}}$ ligand is disordered over two well-defined positions (see Figure S36, ESI). Two closely related $\mathrm{Au}(\mathrm{III})$ acetonate complexes, (phenylpyridine) $\mathrm{Au}(\mathrm{X})\left(\mathrm{CH}_{2} \mathrm{COMe}\right)\left(\mathrm{X}=\mathrm{Cl}\right.$ or $\mathrm{NO}_{3} ; \mathrm{CH}_{2} \mathrm{COMe}$ trans to ppy- $\left.N\right)$, have been structurally characterized. ${ }^{63}$ Complex 6 also exhibits a slightly distorted square planar coordination geometry, with a 5-membered ring chelate bond angle of 81.69(9) ${ }^{\circ}$. The Auligand distances Au1-N1, Au1-C1, and Au1-O2 are again within the ranges that have been observed in the related $\mathrm{Au}(\mathrm{III})$-tpy complexes. ${ }^{48,53,61} \mathrm{The} \mathrm{Au}-\mathrm{C}\left(\mathrm{sp}^{3}\right)$ bond distance, $\mathrm{Au} 1-\mathrm{C} 13$, is 2.069(2) $\AA$ which is somewhat longer than the $\mathrm{Au}-\mathrm{C}\left(\mathrm{sp}^{3}\right)$ bond distances trans to tpy- $N$ in our Au(III)-tpy complexes (range 2.038(4)-2.042(3) A) and quite similar to those observed in the $\mathrm{Au}(\mathrm{III})$ acetonate complexes (2.067(7) $\AA$ for $\mathrm{X}=\mathrm{Cl}$ and 2.059(5) $\AA$ for $\mathrm{X}=\mathrm{NO}_{3}{ }^{63}$ ). The

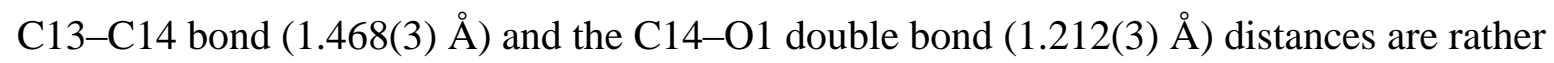
close to the corresponding distances in aldehydes, $1.510(8) \AA$ and 1.192(5) $\AA$, respectively. ${ }^{62}$ The crystal structure displays parallel, displaced $\pi-\pi$ stacking along the $b$ direction, with a distance between the parallel planes of $3.485 \AA$.

Interestingly, it was found that the enolate complex 6, when dissolved in $\mathrm{DOAc}^{\mathrm{F}}$, also catalyzed the addition of DOAc ${ }^{\mathrm{F}}$ to acetylene (ca. 7 turnovers, $24 \mathrm{~h}$ ). During this reaction, substantial decomposition to form unidentified products occurred. 


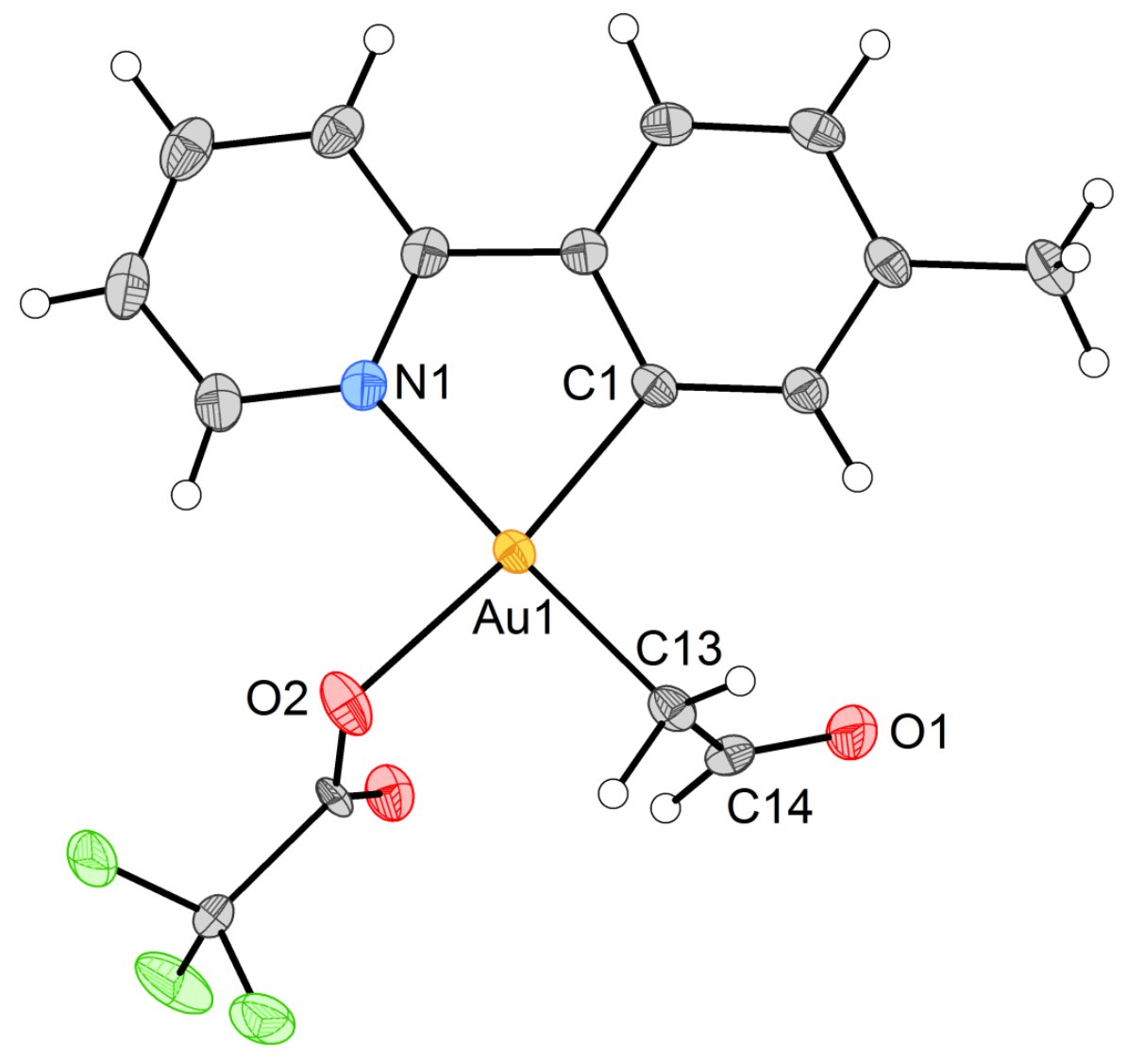

Figure 3. ORTEP drawing of $\mathrm{Au}(\mathrm{III}) \mathrm{C}$-bonded enolate complex 6, with $50 \%$ probability ellipsoids. Selected bond distances $[\AA]$ and angles $\left[{ }^{\circ}\right]$ : Au1-N1, 2.090(2); Au1-C1, 2.006(2); Au1-O2, 2.1016(17); Au1-C13, 2.069(2); C13-C14, 1.468(3); C14O1, 1.212(3); N1-Au1-O2, 91.19(8); C1-Au1-N1, 81.69(9); C1-Au1-C13, 95.22(9); C13-Au1-O2, 91.90(8); C1-Au1-O2, 171.73(8); C13-Au1-N1, 176.91(8); Au1-C13-C14, 108.68(16); C13-C14-O1, 125.8(2); Au-C13-C14-O1, 111.9(2). The $\mathrm{OAc}^{\mathrm{F}}$ trans to $\mathrm{C} 1$ is disordered (see $\left.\mathrm{ESI}\right)$.

A Double Insertion Mechanism for Catalysis? The experimental results described thus far have demonstrated that in addition to $\mathbf{1}$, the two complexes $\mathbf{3}$ and $\mathbf{6}$, with $-\mathrm{CH}=\mathrm{CHOAc}{ }^{\mathrm{F}}$ or $-\mathrm{CH}_{2} \mathrm{CHO}$ trans to tpy- $N$, respectively, were catalytically active, with no detectable intermediates in the case of $\mathbf{3}$. This led us to surmise that the "real" catalytic site actually might be the kinetically available coordination site trans to tpy- $C$, and that the apparent catalysis by $\mathbf{1}$ occurred only via its initial transformation to $\mathbf{3}$. Further support for this was obtained when $\mathrm{Au}(\mathrm{tpy})\left(\mathrm{NTf}_{2}\right)(\mathrm{Me})$, prepared in situ by treatment of previously described ${ }^{64} \mathrm{Au}(\mathrm{tpy})(\mathrm{Br})(\mathrm{Me})$ with $\mathrm{AgNTf}_{2}$, was seen to cause the formation of vinyl trifluoroacetate from acetylene in $\mathrm{HOAc}^{\mathrm{F}}$ (albeit only ca. 1 turnover, during $15 \mathrm{~h}$ ), again with no detectable intermediates by ${ }^{1} \mathrm{H}$ NMR. Also in this case, several other unidentified products were obtained; no attempts were made to elucidate this any further.

The experimental results therefore led us to postulate a modified reaction mechanism for the catalysis. Scheme 7 shows a double-insertion mechanism that appears to be consistent 
with experimental results described thus far. Here, the first insertion (a) generates the vinyl complex 3 which, consistent with observations, does not undergo protolytic cleavage (b). Instead, a second insertion (c) provides an unobserved divinyl complex $\mathbf{7}$ which undergoes protolytic cleavage of the vinyl group trans to tpy- $C$, furnishing vinyl trifluoroacetate with concomitant regeneration of catalytically active $\mathbf{3}$. Thus, the catalytic cycle involves $\mathbf{3}$ and $\mathbf{7}$, whereas 1 merely acts as a precatalyst. The unobserved divinyl complex 7 would nicely account for the formation of $\mathbf{5}$ via a reductive elimination pathway.

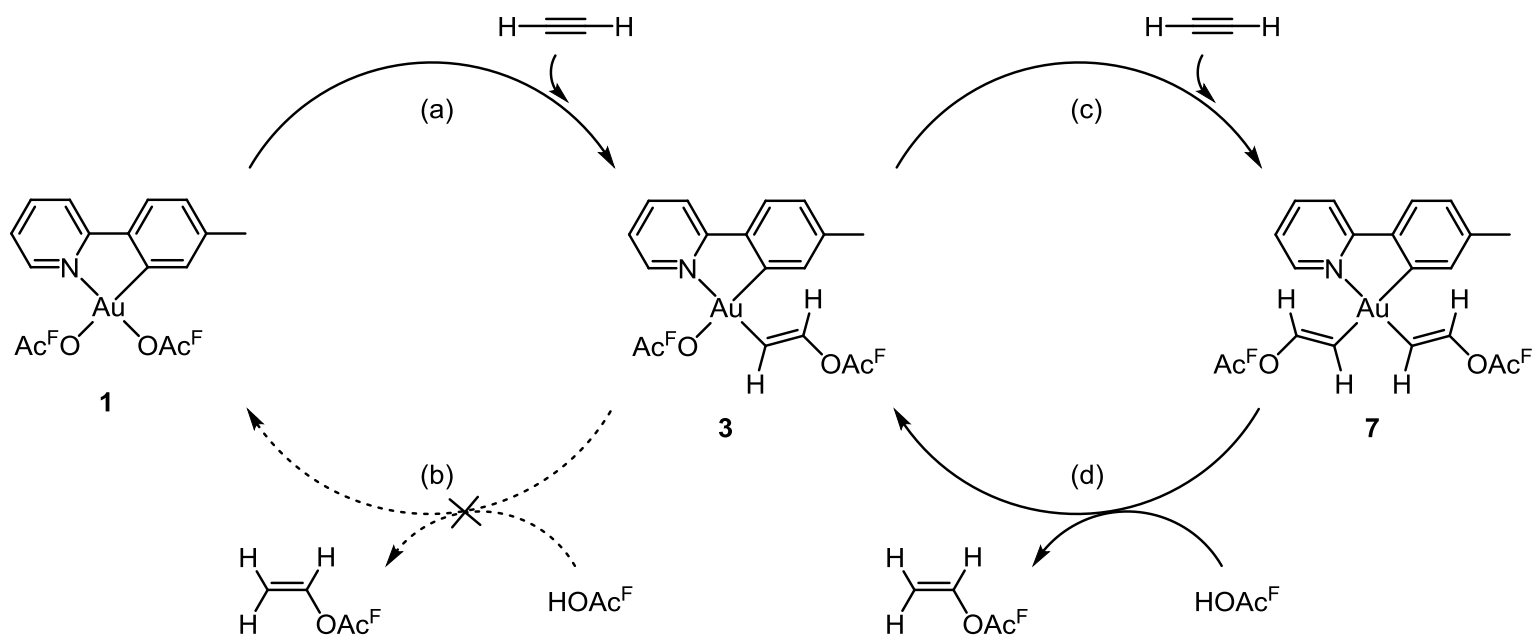

Scheme 7. Double insertion mechanism for the trifluoroacetylation of acetylene catalyzed by $\mathbf{3}$, with $\mathbf{1}$ acting as a precatalyst.

In order to experimentally test the proposed double-insertion hypothesis by ${ }^{1} \mathrm{H}$ NMR, a labelling experiment was designed (Scheme 8a). If the double insertion pathway operates, then the reaction of $\mathbf{3}$ with acetylene- $d_{2}$ in $\mathrm{HOAc}^{\mathrm{F}}$ should provide vinyl trifluoroacetate- $d_{2}$, $(Z)-\mathrm{CHD}=\mathrm{CD}\left(\mathrm{OAc}^{\mathrm{F}}\right)\left(\mathbf{4}-\boldsymbol{d}_{\mathbf{2}}\right)$, from catalysis trans to tpy- $C$ during all catalytic cycles including the first one. In contrast, catalysis trans to tpy- $N$ would furnish non-deuterated vinyl trifluoroacetate during the first cycle, then dideuterated during following cycles. Acetylene- $d_{2}$ was prepared from $\mathrm{CaC}_{2}$ and $\mathrm{D}_{2} \mathrm{O}$ by adaption of a reported procedure. ${ }^{65}$ When acetylene- $d_{2}$ was bubbled through a solution of $\mathbf{3}$ in $\mathrm{HOAc}^{\mathrm{F}}, \mathbf{4}-\boldsymbol{d}_{\mathbf{2}}$ was formed as the dominant product during the first turnover, as inferred from the appearance of a broad singlet at the chemical shift $\delta 4.96$ for the proton located trans to the $\mathrm{OAc}{ }^{\mathrm{F}}$ group in vinyl trifluoroacetate. There was no indication of vinyl trifluoroacetate- $d_{0}(4)$, which might arise from protolytic cleavage of the Au-vinyl bond in 3, during the first and most diagnostic turnover. However, after the first turnover and more extensive reaction times, acetylene- $d_{1}$ and $d_{0}$ were seen to slowly form giving rise to concomitant generation of $4-\boldsymbol{d}_{\mathbf{1}}$ and non-deuterated $\mathbf{4}$, presumably due to $\mathrm{D} / \mathrm{H}$ exchange on acetylene in solution or $\pi$-bonded at Au. Thus, strong support is provided to the proposed double-insertion catalytic pathway, in which the catalysis actually occurs trans to 
tpy- $C$ (Scheme 7, rightmost cycle), and not trans to tpy- $N$ as might be anticipated at first glance. The occurrence of some residual reactivity in the position trans to tpy- $N$ cannot be excluded completely.

(a)
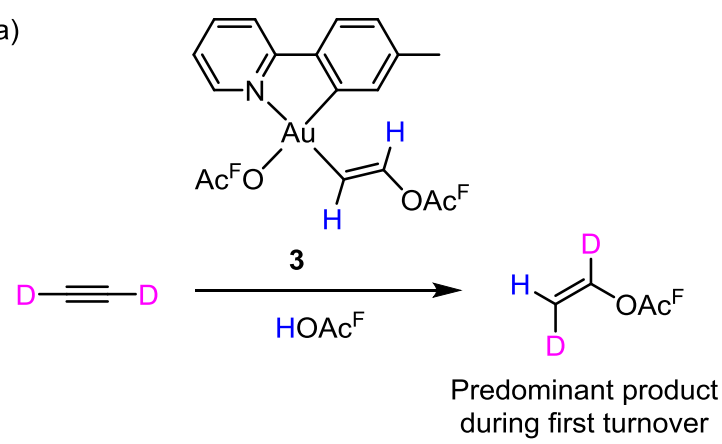

(b)
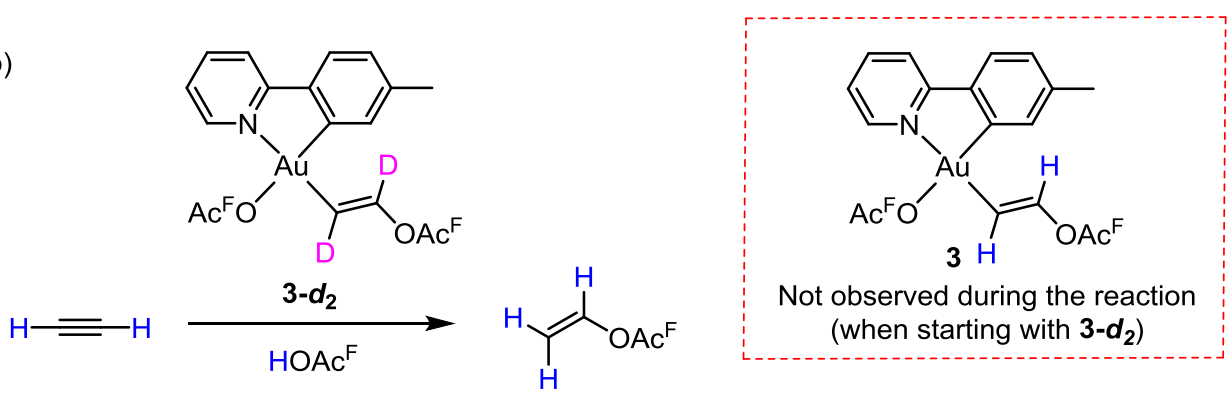

Scheme 8. Deuterium labelling experiments corroborate catalysis trans to tpy- $C$.

Due to the mentioned complications of the (presumably Au(III)-promoted) D/H exchange on acetylene, a complementary experiment was performed which circumvented this problem. When 3- $\boldsymbol{d}_{\mathbf{2}}$ was reacted with acetylene- $d_{0}$ in the presence of $\mathrm{HOAc}^{\mathrm{F}}$, no evidence for formation of unlabeled $\mathbf{3}$ was seen at any time of the reaction, neither during the first turnover nor later (Scheme $8 \mathrm{~b}$ ). This suggests that no protolytic cleavage of the Au-vinyl bond trans to tpy- $N$ occurs, and that no subsequent insertion of acetylene- $d_{0}$ has occurred at this position. Furthermore, signals arising from 5 were observed also in this reaction ( $\delta 6.35$ and ca 7.5$)$; however, the splitting pattern of the $\delta 6.35$ signal due to the proton $\beta$ to $\mathrm{OAc}^{\mathrm{F}}$ was now simplified to resemble a doublet of triplets with a trans ${ }^{3} J_{\mathrm{HH}}$ coupling of $12.2 \mathrm{~Hz}$ and ${ }^{3} J_{\mathrm{HD}}$ coupling of $1.4 \mathrm{~Hz}$, and the partially overlapping signal due to the proton $\alpha$ to $\mathrm{OAc}^{\mathrm{F}}$ resembled a doublet (ESI, Figure S26). This suggests that $\mathbf{5}-\boldsymbol{d}_{\mathbf{2}}$ had formed by a reductive elimination of one vinyl- $d_{2}$ group trans to tpy- $N$ and one vinyl- $d_{0}$ group trans to tpy- $C$.

The finding that $\mathbf{3}, \mathbf{6}$, as well as the methyl analogue $\mathrm{Au}(\mathrm{tpy})\left(\mathrm{NTf}_{2}\right)(\mathrm{Me})$ all catalyze the formation of vinyl trifluoroacetate is now readily rationalized in that catalysis proceeds via coordination of acetylene, nucleophilic attack by ${ }^{-} \mathrm{OAc}{ }^{\mathrm{F}}$ and protolysis trans to tpy- $C$. By virtue of the considerably greater trans effect of tpy- $C$ (an aryl group) than tpy- $N$ (pyridine), 
hydrocarbyl groups bonded trans to the tpy- $C$ site should be more prone to protolytic cleavage than groups bonded trans to tpy- $N$. Differences in thermodynamic and kinetic trans effects of tpy- $C$ vs. tpy- $N$ have been observed and discussed previously; ${ }^{66}$ here, these effects prove to be crucial for catalytic reactions of acetylene. These effects will be further discussed in the context of DFT calculations of the mechanism (vide infra).

In view of the proposed mechanism, the formation of $\mathbf{5}$ and $\mathrm{D}_{2}$ tpy ${ }^{+}$is readily accounted for as catalyst deactivation products, arising from the divinyl complex 7 (Scheme 9). We recently reported that $\mathrm{Au}(\mathrm{tpy}) \mathrm{Me}_{2}$ undergoes protolytic cleavage already at $-78{ }^{\circ} \mathrm{C} .{ }^{43}$ The protolysis caused the selective cleavage of the $\mathrm{Au}-\mathrm{C}(\mathrm{tpy})$ bond, which was followed by reductive elimination of ethane from the resulting putative 3-coordinate intermediate; $\mathrm{Au}-\mathrm{Me}$ protolysis was not observed at all. If 7 behaves analogously, the 3-coordinate specie in the middle of Scheme 9 would be generated, and reductive elimination of the two vinyl groups would furnish $\mathbf{5}$, followed by complete decomposition and formation of $\mathrm{H}_{2} \mathrm{tpy}^{+}$and $\mathrm{Au}(\mathrm{s})$ (the mode of eventual $\mathrm{Au}(\mathrm{s})$ formation from $\mathrm{Au}(\mathrm{I})$ is unknown). Apparently, protolytic cleavage of the $\mathrm{Au}-\mathrm{Me}$ bonds in $\mathrm{Au}\left(\right.$ tpy) $\mathrm{Me}_{2}$ is kinetically disfavored relative to the cleavage of the $\mathrm{Au}-$ $\mathrm{C}$ (tpy) bond, reflecting a preference for protolysis of $\mathrm{Au}-\mathrm{C}\left(\mathrm{sp}^{2}\right)$ bonds. On the other hand, protolysis at 7 may occur competitively at two $\mathrm{Au}-\mathrm{C}\left(\mathrm{sp}^{2}\right)$ bonds. Of these, protolysis of $\mathrm{Au}-$ $\mathrm{C}$ (vinyl) trans to tpy- $C$ must be favored over protolysis at $\mathrm{Au}-\mathrm{C}(\mathrm{tpy})$. This is required in order for catalysis to be kinetically preferred over deactivation. The trans effects of tpy- $C v s$. tpy- $N$ causes protonation of $\mathrm{Au}-\mathrm{C}($ vinyl) trans to tpy- $N$ to be even slower.

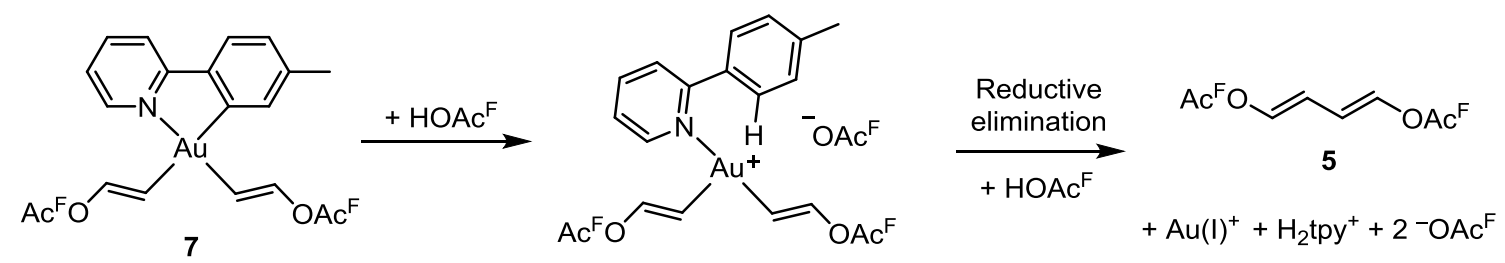

Scheme 9. Suggested decomposition pathway for the divinyl complex $\mathbf{7}$ furnishing $\mathbf{5}$.

Nanoparticle Involvement? The results discussed so far are readily interpreted in terms of the proposed double insertion pathway. Nevertheless, there is always a concern that catalysis may be effected by Au nanoparticles, ${ }^{67,68}$ whether originally present as a low-level contaminant, or as a result of catalyst decomposition. Decomposition eventually occurred in the systems described, and during the reaction a dark brown to black precipitate appeared which is probably Au particles. This is particularly relevant, considering the activity of metallic gold as a catalyst for vinyl chloride production from acetylene and $\mathrm{HCl}^{19,21}$ Whereas 
it is readily envisaged that Au particles may be active catalysts also in our system, this scenario does not appear to rationalize the results of the mechanistic investigation. In particular, the compelling evidence gained from the labeling experiments support the notion of a process catalyzed by molecular complexes. Nevertheless, a series of control experiments were conducted in order to assess to what extent Au particles might be involved. The Au particles originating from the catalyst decomposition were isolated and their reactivity was investigated under the same reaction conditions as described for the homogeneous system. Upon comparing the outcome of these experiments with the homogenous system, it was found that the Au particles may be responsible for maximum ca. 4-13\% of the total production of 4 . Full details of these control experiments are given in the ESI.

\section{DFT Calculations: Reaction Mechanism.}

A computational study of the catalytic trifluoroacetoxylation of acetylene with $\mathbf{1}$ was performed using DFT (PBE0-D3/SDD(f),6-311+G**, with structures optimized in solvent with the continuum SMD model; see Computational Details) calculations to test the mechanistic proposal shown in Scheme 7, and to provide additional insight into the different reactivity of acetylene and ethylene. Following our previous work ${ }^{48}$ on the ethylene insertion into the $\mathrm{Au}-\mathrm{OAc}{ }^{\mathrm{F}}$ bond in $\mathrm{Au}(\mathrm{tpy})\left(\mathrm{OAc}{ }^{\mathrm{F}}\right)_{2}$, and consistent with the formation of $\mathbf{3}$ during the catalytic cycle, the mechanism which had been obtained with ethylene was the foundation for computations using acetylene instead. This mechanism is a two-step process in which an associative substitution of ${ }^{-} \mathrm{OAc}^{\mathrm{F}}$ by the substrate is followed by external nucleophilic addition (Scheme 1, path A). This ligand substitution-nucleophilic addition sequence occurs selectively in the position trans to tpy- $N$. However, as was done for ethylene, acetylene insertion trans to tpy- $N$ as well as trans to tpy- $C$ were both considered in order to evaluate the energetic differences of changing the substrate (Figure 4). 


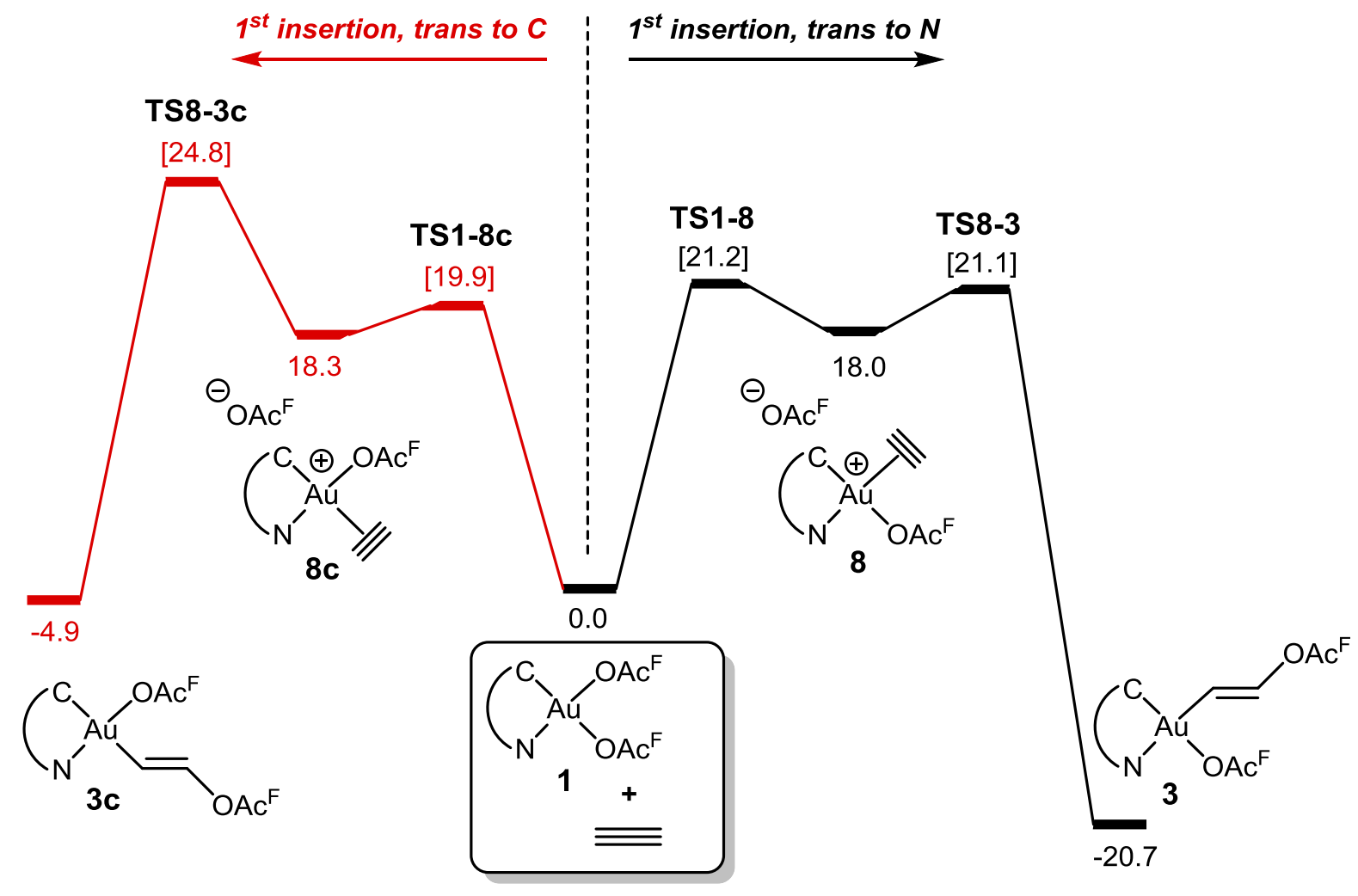

Figure 4. Free energy profile (in $\mathrm{kcal} \mathrm{mol}^{-1}$ ) for the first insertion of acetylene trans to tpy- $C$ (red) and trans to tpy- $N$ (black). The energies of all minima and transition states in [brackets] are computed with $\mathrm{HOAc}^{\mathrm{F}}$ as the solvent. Transition state geometries for the reaction steps that are inferred to occur (insertion trans to tpy- $N$ ) are shown in Figure 6.

The first step of the reaction, which is the ligand substitution, has a rather similar energy profile when the reaction occurs trans to tpy- $N$ or trans to tpy- $C$, with energies for 8 and $8 \mathbf{c}$ of $c a 18 \mathrm{kcal} \mathrm{mol}^{-1}$. In contrast, the nucleophilic addition step is kinetically and thermodynamically preferred trans to tpy- $N$ by 3.7 and $15.8 \mathrm{kcal} \mathrm{mol}^{-1}$, respectively. This is consistent with the observed insertion of acetylene trans to tpy- $N$ and therefore the spontaneous formation of $\mathbf{3}$ during the reaction. In addition, this reaction is clearly irreversible since the energy barrier for the reverse process is $>40 \mathrm{kcal} \mathrm{mol}^{-1}$.

As proposed earlier, two scenarios could be envisioned for completion of the catalytic trifluoroacetoxylation of acetylene from 3 after the observed, initial insertion trans to tpy- $N$ : (1) protolytic cleavage of the Au-vinyl bond (Scheme 4); and (2) insertion of a second molecule of acetylene into the $\mathrm{Au}-\mathrm{OAc} \mathrm{c}^{\mathrm{F}}$ bond trans to tpy- $C$ followed by protolytic cleavage of the resulting Au-vinyl bond (Scheme 7, c and d). These pathways were computationally explored using 3 as the energy base level (Figure 5), since as pointed out above, the formation of this species from $\mathbf{1}$ is irreversible. Protolytic cleavage of the Au-vinyl bond in $\mathbf{3}$, which is trans to $\mathrm{N}$, has an energy barrier (TS3-9) of $24.8 \mathrm{kcal} \mathrm{mol}^{-1}$. Although this barrier could be 
surpassable, it appears too high for a reaction which occurs readily at ambient temperature, and indeed no formation of the expected products 1 and 4 was observed by addition of $\mathrm{HOAc}^{\mathrm{F}}$ to 3. In contrast, the insertion of a second molecule of acetylene, this time trans to tpy- $C$, has a somewhat lower energy barrier of $22.7 \mathrm{kcal} \mathrm{mol}^{-1}$ (TS10c-7). This energy is 2.1 $\mathrm{kcal} \mathrm{mol}^{-1}$ lower than the same process (TS8-3c) from 1, in which the position trans to tpy- $N$ is occupied by an $\mathrm{OAc}^{\mathrm{F}}$ ligand. This energy difference, combined with the fact that the position trans to tpy- $N$ is blocked towards insertion at least by the coordination/nucleophilic attack pathway, allows the second insertion, now trans to tpy- $C$, and subsequent formation of the unobserved divinyl complex 7. Protolytic cleavage of the vinyl ligand trans to tpy- $C$ from 7 has a rather low barrier of $14.3 \mathrm{kcal} \mathrm{mol}^{-1}$ (TS7-11), which is consistent with the nonaccumulation of $\mathbf{7}$ during the catalytic reaction. This step leads to the formation of $\mathbf{1 1}$, from which substitution of coordinated 4 by the ${ }^{-} \mathrm{OAc}^{\mathrm{F}}$ anion promotes the forward, strongly exergonic reaction and regenerates the activated catalyst $3\left(\Delta \mathrm{G}=-19.7 \mathrm{kcal} \mathrm{mol}^{-1}\right.$, not shown in Figure 5).

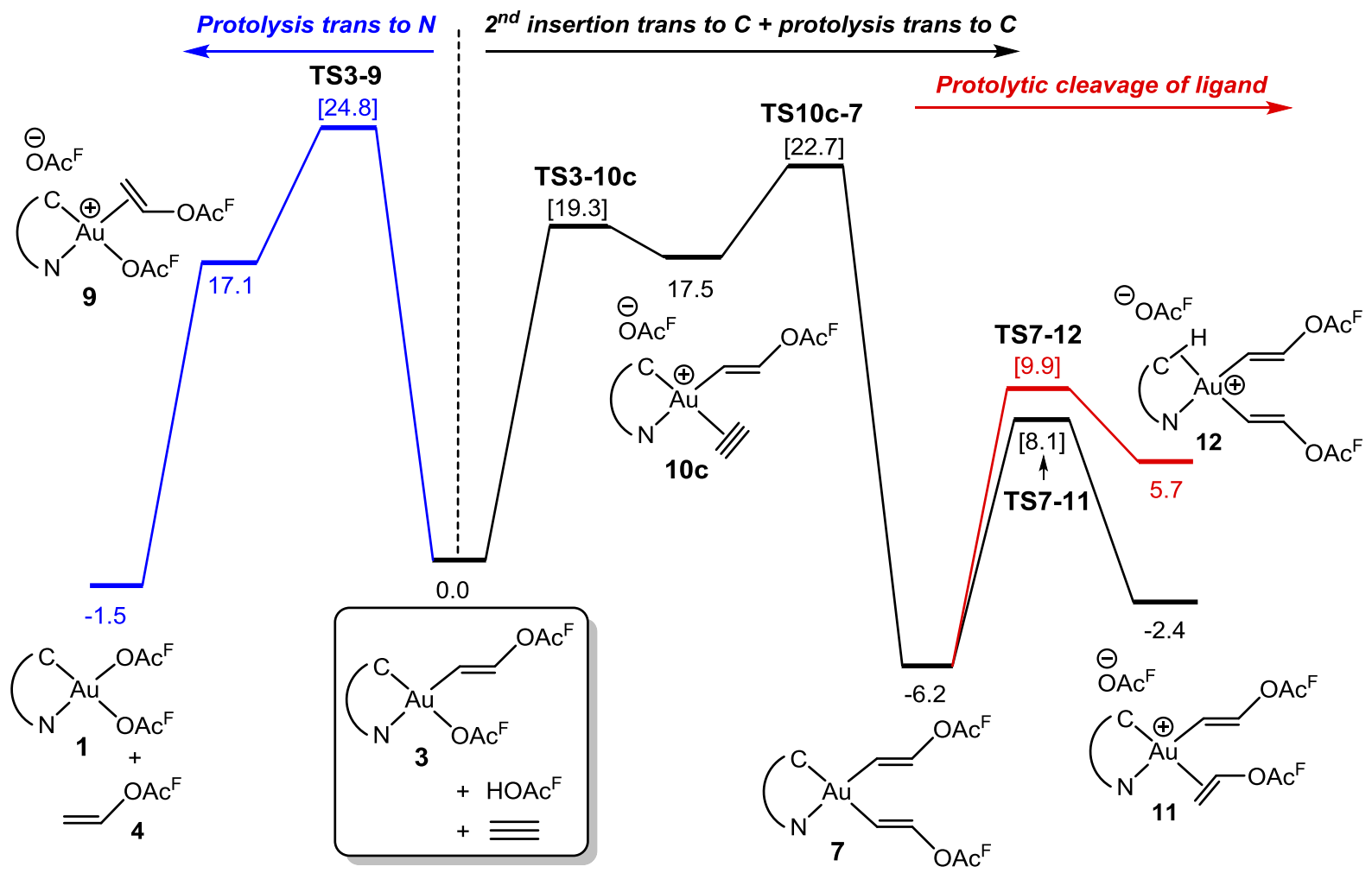

Figure 5. Free energy profile (in $\mathrm{kcal} \mathrm{mol}^{-1}$ ) for the protolytic cleavage of the $\mathrm{Au}$-vinyl bond in $\mathbf{3}$ (blue), the insertion of acetylene into the $\mathrm{Au}-\mathrm{OAc}{ }^{\mathrm{F}}$ bond in $\mathbf{3}$ furnishing $\mathbf{7}$ followed by protolytic cleavage of the $\mathrm{Au}$-vinyl bond trans to tpy-C (black), and protolytic cleavage of the $\mathrm{Au}-\mathrm{C}(\mathrm{tpy})$ bond (red) in 7. The energies of all minima and transition states in [brackets] are computed in $\mathrm{HOAc}^{\mathrm{F}}$. Transition state geometries for the observed reaction steps (reaction trans to tpy-C) are shown in Figure 6. In order to maintain mass and charge balance, the energies of additional $\mathrm{HOAc} c^{\mathrm{F}},{ }^{-} \mathrm{OAc}{ }^{\mathrm{F}}$, and/or acetylene have been included in the calculations where needed. 
The more facile protolytic cleavage of the Au-vinyl bond trans to tpy- $C$ (TS7-11; $\Delta \mathrm{G}^{t}$ $\left.=14.3 \mathrm{kcal} \mathrm{mol}^{-1}\right)$ compared to the one trans to tpy- $N\left(\mathbf{T S 7 - 1 1} \mathbf{c} ; \Delta \mathrm{G}^{\ddagger}=26.8 \mathrm{kcal} \mathrm{mol}^{-1}\right.$, not shown in Figure 5) in 7, can be explained by the higher trans effect of the former site of the chelate compared to the latter. In agreement with this, the Au-C(tpy) bond is also prone to be protolytically cleaved in complex 7 since it is trans to the vinyl- $C$. The free energy barrier for protolytic cleavage at tpy- $C$ is $16.1 \mathrm{kcal} \mathrm{mol}^{-1}$ (TS7-12), which is ca $2 \mathrm{kcal} \mathrm{mol}^{-1}$ higher than for the protolytic cleavage of the Au-vinyl bond trans to tpy- $C$ (TS7-11). This difference, albeit small, is consistent with the catalytic hydrotrifluoroacetoxylation of acetylene being preferred (i.e., significant turnover numbers) over catalyst deactivation. Nevertheless, the closeness of the two energy barriers is consistent with the observation of $\mathbf{5}$ during the catalysis, since formation of the resulting tricoordinated $\mathrm{Au}(\mathrm{III})$ species promotes reductive elimination processes. $^{15,69-73}$
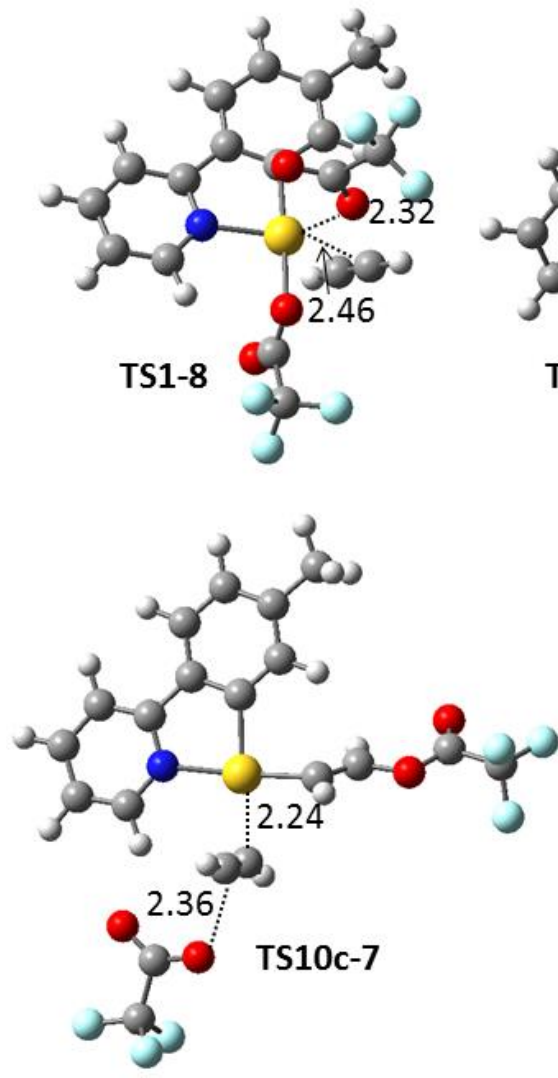
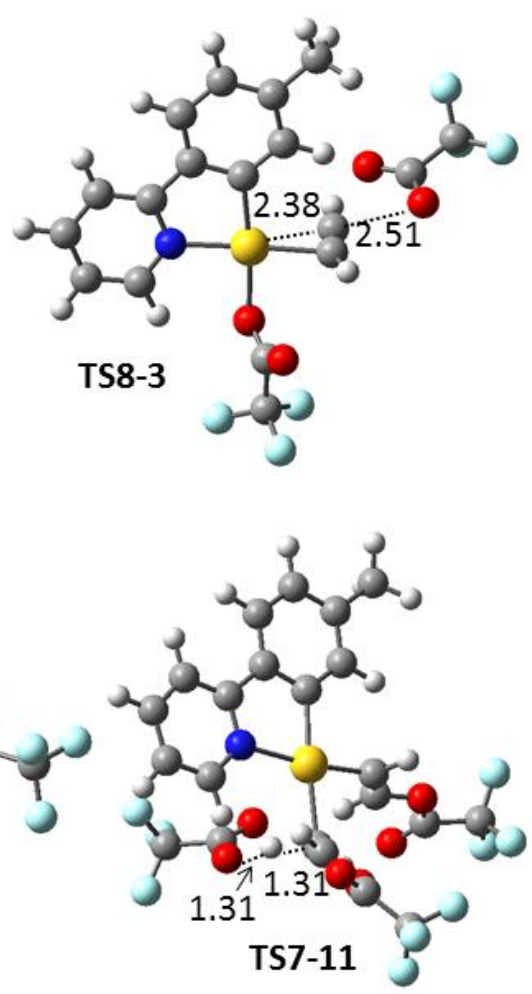
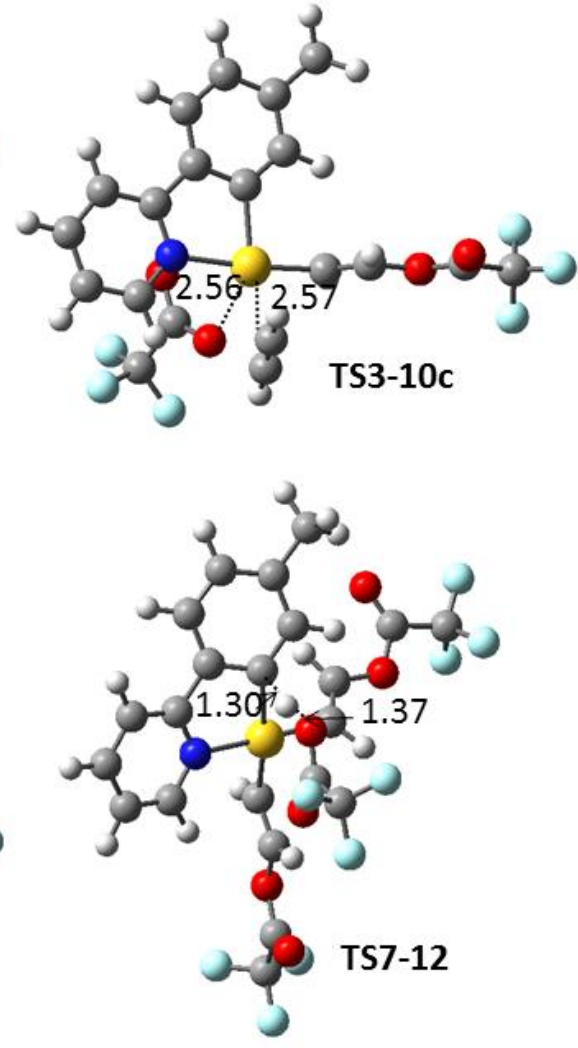

Figure 6. Transition state geometries involved in the reaction of $\mathbf{1}$ with acetylene. Distances in $\AA$.

Overall, the computational results on the reaction of $\mathbf{1}$ with acetylene in $\mathrm{HOAc}^{\mathrm{F}}$ are consistent with the catalytic mechanism proposed in Scheme 7, in which the facile, observed acetylene insertion trans to tpy- $N$ should be considered to be an activation of the pre-catalyst 
1. The catalytic trifluoroacetoxylation reaction takes place trans to tpy- $C$ in the true catalyst 3 . In order to explain why such catalytic reactivity is not observed with ethylene, ${ }^{48}$ the thermodynamics of the three fundamental steps involved in the catalytic cycle, ligand substitution, nucleophilic attack, and protolytic cleavage (A-C in Scheme 10) were computed and compared for the substrates acetylene and ethylene (Table 1). The substitution of an OAc ${ }^{\mathrm{F}}$ ligand by the substrate (step A) shows only small variations in free energy changes for both acetylene and ethylene, in both trans to tpy- $N$ and trans to tpy- $C$ positions. By stark contrast, the nucleophilic addition of ${ }^{-} \mathrm{OAc}{ }^{\mathrm{F}}$ (step B) at the substrate bound trans to tpy- $N$ is more favorable by $\mathrm{ca} 16 \mathrm{kcal} \mathrm{mol}^{-1}$ than addition to the substrate bound trans to tpy- $C$ regardless whether acetylene or ethylene is the substrate. Finally, and importantly, the nucleophilic addition to coordinated acetylene is favored over addition to coordinated ethylene by $\mathrm{ca} 16$ kcal $\mathrm{mol}^{-1}$, applicable to reactions trans to tpy- $C$ as well as trans to tpy- $N$. The latter preference was also observed in our recent computational work on the insertion of ethylene and acetylene into $\mathrm{Au}-\mathrm{X}$ bonds $(\mathrm{X}=\mathrm{Cl}, \mathrm{Me}$, and $\mathrm{H})$ in simple $\mathrm{Au}(\mathrm{III})$ model complexes. ${ }^{15}$ The strong thermodynamic preference for nucleophilic addition to acetylene compared to ethylene is the result of two contributing and reinforcing factors. First, there is a lower energy penalty for breaking one $\pi$-bond component in a triple bond compared to breaking the $\pi$-bond in a double bond. Second, the nucleophilic attack generates a stronger $\mathrm{Au}-\mathrm{C}\left(\mathrm{sp}^{2}\right)$ bond from acetylene than the $\mathrm{Au}-\mathrm{C}\left(\mathrm{sp}^{3}\right)$ bond which results from ethylene. ${ }^{74}$ These large energy differences depend on the substrate in question as well as on the position of the bonded substrate (trans to tpy- $N$ vs tpy- $C$ ) and have remarkable consequences for the insertion reactions (step $\mathrm{A}+\mathrm{B}$, Scheme 10). At the position trans to tpy- $N$, a reversible insertion reaction is predicted (and observed ${ }^{48}$ ) with ethylene, but the insertion will be irreversible with acetylene under ambient conditions. On the other hand, trans to tpy- $C$, the insertion is endergonic for ethylene but exergonic for acetylene (vide infra). Furthermore, in the ligand protolysis step (C, Scheme 10), the thermodynamics is significantly affected only by whether protolysis occurs trans to tpy- $N$ or trans to tpy- $C$. Protolytic cleavage of the Au-C bond is thermodynamically preferred trans to tpy- $C$ by $c a 17 \mathrm{kcal} / \mathrm{mol}$ for both acetylene and ethylene, and is exergonic in all cases. Only small variations were observed by changing the other non-tpy ligand ( $\mathrm{X}$ in Scheme 10 and Table 1) from $\mathrm{OAc}^{\mathrm{F}}$ to $\mathrm{CH}=\mathrm{CHOAc}^{\mathrm{F}}$ or $\mathrm{CH}_{2} \mathrm{CH}_{2} \mathrm{OAc}{ }^{\mathrm{F}}$. 
(A)

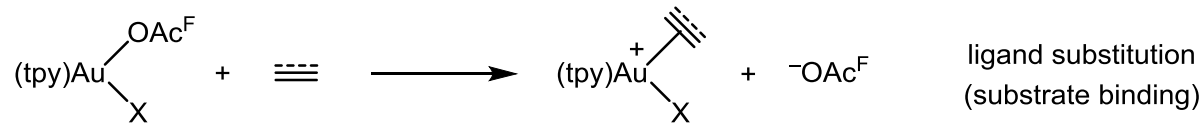

(B)

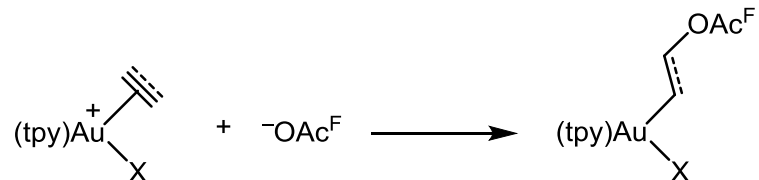

(C)<smiles>[X][14CH2]/C=C/O[14CH3]</smiles>

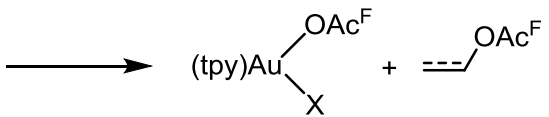

protolytic cleavage

Scheme 10. The three reaction steps for the catalytic trifluoroacetoxylation of acetylene and ethylene. $\mathrm{X}=\mathrm{OAc} \mathrm{c}^{\mathrm{F}}$, $\mathrm{CH}=\mathrm{CHOAc}^{\mathrm{F}}$, or $\mathrm{CH}_{2} \mathrm{CH}_{2} \mathrm{OAc}{ }^{\mathrm{F}}$.

Table 1. Calculated free energy changes $\left(\mathrm{kcal} \mathrm{mol}{ }^{-1}\right)$ for reactions (A)-(C) in Scheme 10. ${ }^{a}$

\begin{tabular}{|c|c|c|c|c|c|}
\hline \multirow[b]{2}{*}{$-X=$} & \multirow[b]{2}{*}{ Reaction } & \multicolumn{2}{|c|}{ Acetylene } & \multicolumn{2}{|c|}{ Ethylene } \\
\hline & & $\begin{array}{l}\text { rxn trans } \\
\text { to tpy- } C\end{array}$ & $\begin{array}{l}\text { rxn trans } \\
\text { to tpy- } N\end{array}$ & $\begin{array}{l}\text { rxn trans } \\
\text { to tpy- } C\end{array}$ & $\begin{array}{l}\text { rxn trans } \\
\text { to tpy- } N\end{array}$ \\
\hline \multirow{3}{*}{$-\mathrm{OAc} c^{\mathrm{F}}$} & (A) & 24.5 & 23.7 & 23.6 & 22.4 \\
\hline & (B) & -29.4 & -44.4 & -12.5 & -29.4 \\
\hline & (C) & -17.3 & -1.5 & -22.1 & -4.0 \\
\hline \multirow{3}{*}{$-\mathrm{CH}=\mathrm{CHOAc}{ }^{\mathrm{F}}$} & (A) & 22.0 & 21.8 & - & - \\
\hline & (B) & -28.3 & -43.9 & - & - \\
\hline & (C) & -15.9 & -0.1 & - & - \\
\hline \multirow{3}{*}{$-\mathrm{CH}_{2} \mathrm{CH}_{2} \mathrm{OAc}^{\mathrm{F}}$} & (A) & - & - & 21.3 & 17.0 \\
\hline & (B) & - & - & -11.7 & -25.6 \\
\hline & (C) & - & - & -20.6 & -2.5 \\
\hline \multicolumn{6}{|c|}{$\begin{array}{l}\text { a These values have been computed with the same methodology and without } \\
\text { considering ion-pairs to facilitate comparison. Therefore the data may slightly } \\
\text { differ from the ones in Figure } 4 \text { and } 5 \text { and those published in our previous work } \\
\text { computed in HOAc }{ }^{\mathrm{F}} \text {. }\end{array}$} \\
\hline
\end{tabular}

The thermodynamic data shown in Table 1 and the kinetics already discussed show that the simple catalytic cycle (single insertion + protonation; Scheme 4) will not proceed 
with acetylene. Even though the insertion trans to tpy- $N$ to give $\mathbf{3}$ is preferred, kinetically and thermodynamically (and, in practice, is irreversible) over insertion trans to tpy- $C$ to give 3c (Figure 4), the protolytic Au-vinyl bond cleavage trans to tpy- $N$ in 3, which would complete the cycle, has a higher energy barrier (TS3-9, $24.8 \mathrm{kcal} \mathrm{mol}^{-1}$, Figure 5) than the alternative insertion of acetylene trans to tpy- $C$ in 3 (TS10c-7, $22.7 \mathrm{kcal} \mathrm{mol}^{-1}$, Figure 5), which facilitates the observed entry into the more efficient double cycle mechanism.

By contrast, with ethylene, the insertion trans to tpy- $N$ (previously shown to exhibit reversibility ${ }^{48}$ ) could in principle, after reversal, allow for the considerably less favorable insertion trans to tpy- $C$ to furnish 3c-alk (see Scheme 11), provided that the subsequent protolytic cleavage from this complex could help drive this reaction. However, the computed energy barrier for the protolytic cleavage of the $\mathrm{Au}-\mathrm{C}\left(\mathrm{sp}^{3}\right)$ bond in $\mathbf{3 c}$-alk (Scheme 11, top) is $23.7 \mathrm{kcal} \mathrm{mol}^{-1}$, which is prohibitively high since the formation of $\mathbf{3 c}$-alk from $\mathbf{1}$ is already endergonic by $11.1 \mathrm{kcal} \mathrm{mol}^{-1}\left(=\Delta \mathrm{G}^{\mathrm{A}}+\Delta \mathrm{G}^{\mathrm{B}}\right.$; data from Table 1 , entries for ethylene, $\mathrm{X}=$ $\mathrm{OAc}^{\mathrm{F}}$, trans to tpy-C). Remarkably, when the same reaction was computed from $\mathbf{3 c}$ (Scheme 11 , bottom), the energy barrier for the protolytic cleavage of the $\mathrm{Au}-\mathrm{C}\left(\mathrm{sp}^{2}\right)$ bond in $\mathbf{3 c}$ is only $14.5 \mathrm{kcal} \mathrm{mol}^{-1}$. Thus, there is a significant kinetic preference $\left(\Delta \Delta \mathrm{G}^{\neq} \sim 9 \mathrm{kcal} \mathrm{mol}^{-1}\right)$ for protolysis of the $\mathrm{Au}-\mathrm{C}$ bond in the $\mathrm{Au}-\mathrm{CH}=\mathrm{CHOAc}^{\mathrm{F}}$ fragment compared to $\mathrm{Au}-$ $\mathrm{CH}_{2} \mathrm{CH}_{2} \mathrm{OAc} c^{\mathrm{F}}$, even though the latter is somewhat more favorable thermodynamically $\left(\Delta \Delta \mathrm{G}^{\circ}\right.$ $\sim 1.5 \mathrm{kcal} \mathrm{mol}^{-1}$ ). This is particularly relevant, because the protolytic cleavages in Scheme 11 must compete favorably with the protolytic cleavage at tpy- $C$ in order for catalysis to occur (otherwise, catalyst decomposition takes place, as evidenced by the formation of $\mathbf{5}$ and $\mathrm{H}_{2} \mathrm{tpy}^{+}$ observed experimentally). In 7 (Scheme 7), protolysis at the tpy- $C$ ligand is less favorable than protolytic cleavage of the vinylic group $\mathrm{Au}-\mathrm{CH}=\mathrm{CHOAc}{ }^{\mathrm{F}}$ (TS7-12 vs TS7-11) trans to tpy- $C$. However, the opposite preference is expected in 3c-alk (Scheme 11), for which protolytic cleavage at tpy- $C$ will be favored over $\mathrm{CH}_{2} \mathrm{CH}_{2} \mathrm{OAc}{ }^{\mathrm{F}}$. Indeed, as mentioned earlier, we have reported previously that protolytic cleavage at tpy- $C$ occurs rapidly even at $-60{ }^{\circ} \mathrm{C}$ when $\mathrm{Au}(\mathrm{tpy}) \mathrm{Me}_{2}$ is treated with trifluoromethanesulfonic acid. ${ }^{43}$ 


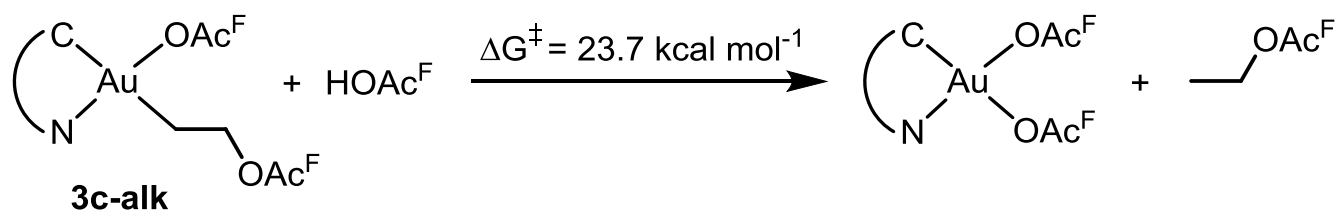

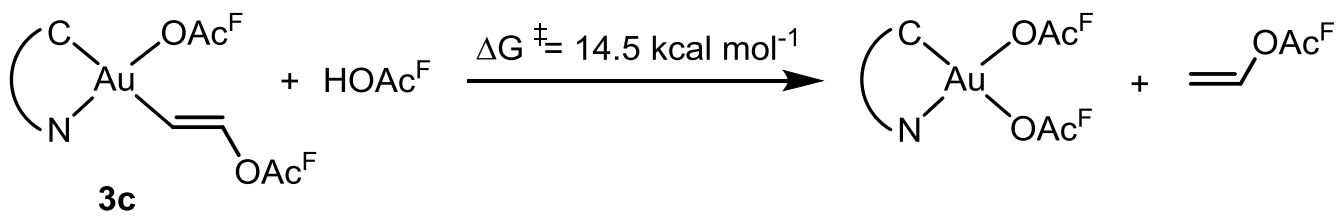

Scheme 11. Protolytic cleavage of $\mathrm{Au}-\mathrm{C}\left(\mathrm{sp}^{3}\right)$ (top) and $\mathrm{Au}-\mathrm{C}\left(\mathrm{sp}^{2}\right)$ (bottom) bonds trans to tpy- $C$. 


\section{CONCLUSIONS}

This study of catalytic acetylene functionalization, combined with our earlier investigation of ethylene insertion reactivity, ${ }^{48}$ at $\mathrm{Au}(\mathrm{tpy})\left(\mathrm{OAc}{ }^{\mathrm{F}}\right)_{2}$ has led to fundamental insight into crucial steps that are involved in the reactivity of $\mathrm{C}-\mathrm{C}$ double and triple bonds at $\mathrm{Au}(\mathrm{III})$. Three fundamental steps are involved in these transformations: (a) substitution of an $\mathrm{OAc}^{\mathrm{F}}$ ligand by acetylene vs. ethylene; (b) nucleophilic attack by ${ }^{-} \mathrm{OAc}{ }^{\mathrm{F}}$ at coordinated acetylene vs. ethylene; and (c) protolytic cleavage of the $\mathrm{Au}-\mathrm{C}\left(\mathrm{sp}^{3}\right)$ vs. $\mathrm{Au}-\mathrm{C}\left(\mathrm{sp}^{2}\right)$ bonds. Experimental and computational results are in excellent agreement and establish that the thermodynamics and kinetics of each of these steps are profoundly affected by the nature of the coordination site trans to where the particular transformation takes place, i.e. trans to tpy$C$ vs. trans to tpy- $N$. Further elaboration and tuning of the chelating ligand, either of its backbone or substitution pattern, should pave the way towards more active and robust $\mathrm{Au}(\mathrm{III})$ catalysts for small-molecule functionalization.

\section{SUPPORTING INFORMATION}

Experimental and computational procedures, characterization, crystallographic, and computational data. This material is available free of charge via the Internet at http://pubs.acs.org.

\section{ACKNOWLEDGMENT}

We gratefully acknowledge financial support from the Research Council of Norway for funding provided through the Centre of Excellence for Theoretical and Computational Chemistry (CTCC; Grant 179568/V30) and for stipends to AN, EL and MSMH (Grants 185513/I30 and 221801/F20), and the Norwegian Metacenter for Computational Science (NOTUR; Grant nn4654k). DB also thanks the EU REA for a Marie Curie Fellowship (Grant CompuWOC/618303). This work was also supported by COST Action CM1205 CARISMA (Catalytic Routines for Small Molecule Activation). GL thanks EPFL and Swiss National Science Foundation for financial support. Furthermore, we would like to thank Roman Tschentscher, SINTEF Materials and Chemistry, for advice with the catalytic experiments, Osamu Sekiguchi, University of Oslo, for performing the MS experiments, and University of Oslo NMR center for giving us generous access to their NMR instruments. 


\section{References}

(1) Hashmi, A. S. K. Chem. Rev. 2007, 107, 3180-3211.

(2) Modern Gold Catalyzed Synthesis; Hashmi, A. S. K.; Toste, F. D., Eds.; Wiley-VCH: Weinheim, 2012.

(3) Hashmi, A. S. K.; Hutchings, G. J. Angew. Chem., Int. Ed. 2006, 45, 78967936.

(4) Brooner, R. E. M.; Widenhoefer, R. A. Angew. Chem., Int. Ed. 2013, 52, 11714-11724.

(5) Dorel, R.; Echavarren, A. M. Chem. Rev. 2015, 115, 9028-9072.

(6) Schmidbaur, H.; Schier, A. Organometallics 2010, 29, 2-23.

(7) Yang, W.; Hashmi, A. S. K. Chem. Soc. Rev. 2014, 43, 2941-2955.

(8) Fürstner, A. Acc. Chem. Res. 2014, 47, 925-938.

(9) Fensterbank, L.; Malacria, M. Acc. Chem. Res. 2014, 47, 953-965.

(10) Zhang, L. Acc. Chem. Res. 2014, 47, 877-888.

(11) Zhang, D.-H.; Tang, X.-Y.; Shi, M. Acc. Chem. Res. 2014, 47, 913-924.

(12) Krause, N.; Winter, C. Chem. Rev. 2011, 111, 1994-2009.

(13) Corma, A.; Leyva-Pérez, A.; Sabater, M. J. Chem. Rev. 2011, 111, 1657-1712.

(14) Rudolph, M.; Hashmi, A. S. K. Chem. Soc. Rev. 2012, 41, 2448-2462.

(15) Balcells, D.; Eisenstein, O.; Tilset, M.; Nova, A. Dalton Trans. 2016, 45, 5504-5513.

(16) Liu, L.-P.; Hammond, G. B. Chem. Soc. Rev. 2012, 41, 3129-3139.

(17) Chiarucci, M.; Bandini, M. Beilstein J. Org. Chem. 2013, 9, 2586-2614.

(18) Johnston, P.; Carthey, N.; Hutchings, G. J. J. Am. Chem. Soc. 2015, 137, 14548-14557.

(19) Davies, C. J.; Miedziak, P. J.; Brett, G. L.; Hutchings, G. J. Chinese J. Catal. 2016, 37, 1600-1607.

(20) Conte, M.; Carley, A. F.; Heirene, C.; Willock, D. J.; Johnston, P.; Herzing, A. A.; Kiely, C. J.; Hutchings, G. J. J. Catal. 2007, 250, 231-239.

(21) Conte, M.; Carley, A. F.; Attard, G.; Herzing, A. A.; Kiely, C. J.; Hutchings, G. J. J. Catal. 2008, 257, 190-198.

(22) Conte, M.; Hutchings, G. J. In Modern Gold Catalyzed Synthesis; Hashmi, A.

S. K., Toste, F. D., Eds.; Wiley-VCH Verlag \& Co. KGaA: Weinheim, 2012, p 1-26.

(23) Zhang, H.; Dai, B.; Wang, X.; Xu, L.; Zhu, M. J. Ind. Eng. Chem. 2012, 18, $49-54$.

1965.

(24) Tolbert, T. L.; Waddell, W. A., Jr. (Monsanto Co.). U.S. Patent 3177243 ,

(25) Dickey, J. B.; Stanin, T. E. (Eastman Kodak Co.). U.S. Patent 2525530, 1950.

(26) Ranieri, B.; Escofet, I.; Echavarren, A. M. Org. Biomol. Chem. 2015, 13,

(27) Kumar, R.; Nevado, C. Angew. Chem., Int. Ed. 2017, 56, 1994-2015.

(28) Henderson, W. Adv. Organomet. Chem. 2006, 54, 207-265.

(29) Huang, L.; Rominger, F.; Rudolph, M.; Hashmi, A. S. K. Chem. Commun. 2016, 52, 6435-6438.

(30) Roth, T.; Wadepohl, H.; Gade, L. H. Eur. J. Inorg. Chem. 2016, 2016, $1184-$ 1191.

(31) Wang, Q.; Jiang, Y.; Sun, R.; Tang, X.-Y.; Shi, M. Chem. Eur. J. 2016, 22, 14739-14745.

(32) Wu, C.-Y.; Horibe, T.; Jacobsen, C. B.; Toste, F. D. Nature 2015, 517, 449454. 
(33) Kawai, H.; Wolf, W. J.; DiPasquale, A. G.; Winston, M. S.; Toste, F. D. J. Am. Chem. Soc. 2016, 138, 587-593.

(34) Hofer, M.; Nevado, C. Eur. J. Inorg. Chem. 2012, 2012, 1338-1341.

(35) Ball, L. T.; Lloyd-Jones, G. C.; Russell, C. A. J. Am. Chem. Soc. 2014, 136,

$254-264$.

(36) Hopkinson, M. N.; Gee, A. D.; Gouverneur, V. Chem. Eur. J. 2011, 17, 8248-

8262.

(37) Wang, W.; Jasinski, J.; Hammond, G. B.; Xu, B. Angew. Chem., Int. Ed. 2010, 49, 7247-7252.

(38) de Haro, T.; Nevado, C. Adv. Synth. Catal. 2010, 352, 2767-2772.

(39) Peng, Y.; Cui, L.; Zhang, G.; Zhang, L. J. Am. Chem. Soc. 2009, 131, 5062-

5063.

(40) Zhang, G.; Peng, Y.; Cui, L.; Zhang, L. Angew. Chem., Int. Ed. 2009, 48,

3112-3115.

(41) Cinellu, M. A.; Minghetti, G.; Cocco, F.; Stoccoro, S.; Zucca, A.; Manassero, M. Angew. Chem., Int. Ed. 2005, 44, 6892-6895.

(42) Liu, Y.; Chen, X.; Zhang, J.; Xu, Z. Synlett 2013, 24, 1371-1376.

(43) Langseth, E.; Scheuermann, M. L.; Balcells, D.; Kaminsky, W.; Goldberg, K. I.; Eisenstein, O.; Heyn, R. H.; Tilset, M. Angew. Chem., Int. Ed. 2013, 52, 1660-1663.

(44) Savjani, N.; Roşca, D.-A.; Schormann, M.; Bochmann, M. Angew. Chem., Int. Ed. 2013, 52, 874-877.

(45) Rekhroukh, F.; Estevez, L.; Bijani, C.; Miqueu, K.; Amgoune, A.; Bourissou, D. Organometallics 2016, 35, 995-1001.

(46) Pernpointner, M.; Hashmi, A. S. K. J. Chem. Theory Comput. 2009, 5, 2717 -

2725.

(47) Lein, M.; Rudolph, M.; Hashmi, A. S. K.; Schwerdtfeger, P. Organometallics 2010, 29, 2206-2210.

(48) Langseth, E.; Nova, A.; Tråseth, E. A.; Rise, F.; Øien, S.; Heyn, R. H.; Tilset, M. J. Am. Chem. Soc. 2014, 136, 10104-10115.

(49) Rekhroukh, F.; Estévez, L.; Bijani, C.; Miqueu, K.; Amgoune, A.; Bourissou, D. Angew. Chem., Int. Ed. 2016, 55, 3414-3418.

(50) Rekhroukh, F.; Estevez, L.; Mallet-Ladeira, S.; Miqueu, K.; Amgoune, A.;

Bourissou, D. J. Am. Chem. Soc. 2016, 138, 11920-11929.

(51) Rekhroukh, F.; Brousses, R.; Amgoune, A.; Bourissou, D. Angew. Chem., Int. Ed. 2015, 54, 1266-1269.

(52) Rezsnyak, C. E.; Autschbach, J.; Atwood, J. D.; Moncho, S. J. Coord. Chem. 2013, 66, 1153-1165.

(53) Holmsen, M. S. M.; Nova, A.; Balcells, D.; Langseth, E.; Øien-Ødegaard, S.;

Tråseth, E. A.; Heyn, R. H.; Tilset, M. Dalton Trans. 2016, 45, 14719-14724.

(54) Raubenheimer, H. G.; Schmidbaur, H. J. Chem. Educ. 2014, 91, 2024-2036.

(55) Egorova, O. A.; Seo, H.; Kim, Y.; Moon, D.; Rhee, Y. M.; Ahn, K. H. Angew.

Chem., Int. Ed. 2011, 50, 11446-11450.

(56) Pintus, A.; Rocchigiani, L.; Fernandez-Cestau, J.; Budzelaar, P. H. M.;

Bochmann, M. Angew. Chem., Int. Ed. 2016, 55, 12321-12324.

(57) Melchionna, M.; Nieger, M.; Helaja, J. Chem. Eur. J. 2010, 16, 8262-8267.

(58) Lauterbach, T.; Asiri, A. M.; Hashmi, A. S. K. Adv. Organomet. Chem. 2014, $62,261-297$.

(59) Roşca, D.-A.; Smith, D. A.; Hughes, D. L.; Bochmann, M. Angew. Chem., Int. Ed. 2012, 51, 10643-10646. 
(60) The crystal system of $\mathbf{3}$ was initially assumed to be base-centered orthorhombic, but during reflection analysis no appropriate orthorhombic space group could be found. Neither could any meaningful crystal structure could be obtained. After careful analysis, the true Bravais lattice was found to be primitive monoclinic, but with cell parameters $a \approx c$ thus emulating the $c$-centered orthorhombic lattice. In addition, all of the examined crystals were twinned by reticular pseudomerohedry via a twofold rotation about the ac face diagonal axis.

(61) Langseth, E.; Görbitz, C. H.; Heyn, R. H.; Tilset, M. Organometallics 2012, $31,6567-6571$.

(62) Allen, F. H.; Kennard, O.; Watson, D. G.; Brammer, L.; Orpen, A. G.; Taylor, R. J. Chem. Soc., Perkin Trans. 2 1987, S1-S19.

(63) Fan, D.; Melendez, E.; Ranford, J. D.; Lee, P. F.; Vittal, J. J. J. Organomet. Chem. 2004, 689, 2969-2974.

(64) Venugopal, A.; Shaw, A. P.; Törnroos, K. W.; Heyn, R. H.; Tilset, M. Organometallics 2011, 30, 3250-3253.

(65) Rupprecht, A. Acta Chem. Scand. 1962, 16, 2189-2194.

(66) Pinter, B.; Van Speybroeck, V.; Waroquier, M.; Geerlings, P.; De Proft, F. Phys. Chem. Chem. Phys. 2013, 15, 17354-17365.

(67) Gold Nanoparticles for Physics, Chemistry and Biology; Louis, C.; Pluchery, O., Eds.; Imperial College Press, 2012.

(68) Bond, G. C.; Louis, C.; Thompson, D. T. Catalysis by Gold; Imperial College Press: London, 2006.

(69) Komiya, S.; Albright, T. A.; Hoffmann, R.; Kochi, J. K. J. Am. Chem. Soc. 1976, $98,7255-7265$.

(70) Scott, V. J.; Labinger, J. A.; Bercaw, J. E. Organometallics 2010, 29, 40904096.

(71) Mankad, N. P.; Toste, F. D. Chem. Sci. 2012, 3, 72-76.

(72) Joost, M.; Zeineddine, A.; Estévez, L.; Mallet-Ladeira, S.; Miqueu, K.; Amgoune, A.; Bourissou, D. J. Am. Chem. Soc. 2014, 136, 14654-14657.

(73) Winston, M. S.; Wolf, W. J.; Toste, F. D. J. Am. Chem. Soc. 2014, 136, $7777-$ 7782.

(74) Clot, E.; Mégret, C.; Eisenstein, O.; Perutz, R. N. J. Am. Chem. Soc. 2006, 128, 8350-8357. 
Table of Contents entry

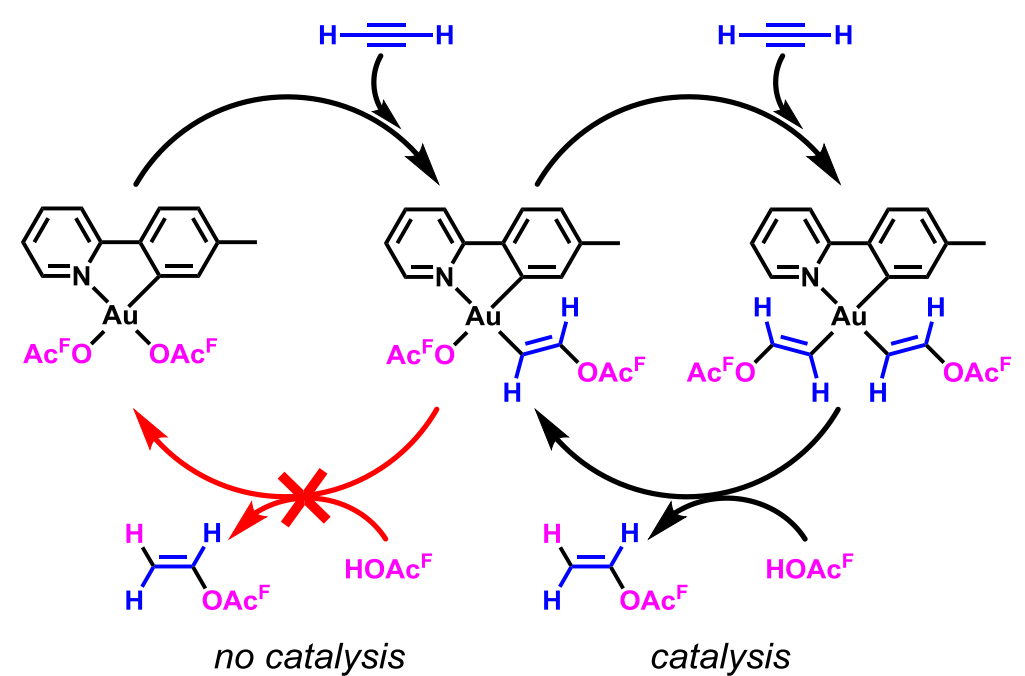

